\title{
Fabrication and Characterization of Titania Nanotube/Cobalt Sulfide Supercapacitor Electrode in Various Electrolytes
}

\author{
Rupashree S. Ray ${ }^{a}$, Biplab Sarma ${ }^{a}$, Abraham L. Jurovitzki ${ }^{a}$, and Mano Misra ${ }^{\text {a, b, } 1}$ \\ ${ }^{a}$ Metallurgical Engineering Department, University of Utah, Salt Lake City, UT 84112, USA \\ ${ }^{\mathrm{b}}$ Chemical Engineering Department, University of Utah, Salt Lake City, UT 84112, USA
}

Keywords: Titania Nanotube, electrochemical Capacitor, charge-discharge, Cobalt sulfide, Pseudocapacitance, Supercapacitor

\begin{abstract}
A facile electrochemical technique has been employed to fabricate titania nanotube (TNT)/cobalt sulfide $(\mathrm{CoS})$ composite electrode for high performance supercapacitor application. The morphology and phase evaluation of the electrode were analyzed using scanning electron microscopy (SEM), X-ray diffraction (XRD), and X-ray photoelectron spectroscopy (XPS) techniques. The pseudocapacitance behavior of the T-NT/CoS composite electrode has been evaluated in four different aqueous electrolytes: $\mathrm{KOH}, \mathrm{KCl}, \mathrm{Na}_{2} \mathrm{SO}_{4}$ and $\mathrm{Na}_{2} \mathrm{SO}_{3}$. Cyclic voltammetric studies in aqueous $\mathrm{KOH}$ electrolyte indicated that a very high specific capacitance $\left(370 \mathrm{~F} \mathrm{~g}^{-1}\right)$ can be achieved in this electrolyte together with excellent cycle stability even after 300 consecutive CV cycles. Further, the capacitance behavior of the T-NT/CoS electrode in $\mathrm{KCl}$, $\mathrm{Na}_{2} \mathrm{SO}_{4}$, and $\mathrm{Na}_{2} \mathrm{SO}_{3}$ electrolytes exhibited a mixture of electric double layer (EDL) and redoxinduced supercapacitance as displayed in the cyclic voltammetry, galvanostatic charge-discharge and electrochemical impedance spectroscopic (EIS) experiments. It was also observed that the capacitance behavior of the composite material is not greatly dependent on the electrolyte used
\end{abstract}

${ }^{1}$ Corresponding author: mano.misra@utah.edu 
except for $\mathrm{Na}_{2} \mathrm{SO}_{3}$ electrolyte where the capacitance value attained is relatively higher than the other electrolytes i.e. $400 \mathrm{~F} \mathrm{~g}^{-1}$ at a fairly high charge-discharge current density of $5 \mathrm{~mA} \mathrm{~cm}^{-2}$. Galvanostatic charge-discharge experiments conducted on the composite electrode suggested stable capacitance behavior with excellent capacitance retention $(\sim 80 \%)$ even after 1000 cycles of continuous charge-discharge cycles in $\mathrm{KCl}, \mathrm{Na}_{2} \mathrm{SO}_{4}$, and $\mathrm{Na}_{2} \mathrm{SO}_{3}$ electrolytes.

\section{Introduction}

Electronic advancements continue to press the need for energy storing devices with high power and high specific energy density [1]. Electrochemical capacitors (EC) are being developed to satisfy this demand as they not only possess higher energy density but also demonstrate longer cycle life compared to batteries and dielectric capacitors [1,2]. EC can be categorized into two primary types by their charge storing mechanism: electric double-layer (EDL) and fast Faradic redox type (pseudocapacitors or supercapacitors) capacitors. In the EDL capacitor, electric energy is stored through the non-faradic charge separation at the electrode/electrolyte interface [2]. EDL based capacitors have been fabricated using carbon, graphene and aerogel, however, they all display relatively low energy densities and poor cycle stability [2,3]. On the other hand, in case of pseudocapacitors, which are based on Faradic mechanism, redox reactions are largely responsible for the energy storage [3,4]. Generally, transition metal oxides (e.g. $\mathrm{RuO}_{2}, \mathrm{NiO}$, $\mathrm{Co}_{2} \mathrm{O}_{3}$ ) have received immense attention for preparation of redox oxide based ECs [4,5]. The presence of multiple valence states in the transition metals can lead to efficient redox-based reaction with the electrolyte, thereby enhancing the specific capacitance in this class of material. Supercapacitors synthesized using hydrous ruthenium oxide have been reported to show high power and energy density coupled with high cycle stability; however, scarcity and higher cost associated with ruthenium prohibits its application in mass/commercial applications [6]. Several 
other transition metal oxides have been investigated as more economical alternative to ruthenium oxide including manganese oxide [7], nickel oxide [8], cobalt oxide [9, 10], molybdenum oxide [11], vanadium oxide [12], and iron oxide [13,14].

Transition metal sulfide based ECs, specifically cobalt and nickel sulfide supercapacitors [15-26] also exhibit remarkably high specific capacitance. Specifically, cobalt and nickel sulfide supercapacitors are studied extensively for this purpose [15-23]. For example, CoS nanowires synthesized through biomolecule-assisted method produced a specific capacitance of $508 \mathrm{~F} \mathrm{~g}^{-1}$ in $3 \mathrm{M} \mathrm{KOH}$ electrolyte with high specific energy, good discharge rate and excellent stability [17]. Similarly, nickel sulfide composite supercapacitors, such as nickel sulfide/Ni-foam as well as nickel sulfide/graphite electrodes, also demonstrated remarkable capacitance properties (> $500 \mathrm{~F}$ $\left.\mathrm{g}^{-1}\right)[25,26]$. It has been observed in these studies that the presence of a porous substrate (graphite, Ni-foam etc) can produce remarkable enhancement in the supercapacitance behavior in many composite electrodes $[25,26]$. The porous substrate facilitates easy migration/diffusion of electrolytes in to the electrode during the electrochemical processes, thereby increasing the reactivity between the electrode/electrolyte systems.

In line with the above discussions, the focus of the present study is to evaluate the supercapacitance behavior of titanium nanotube (T-NT)/CoS composite electrode fabricated by electrodeposition method. T-NT substrate demonstrates several advantages - easy fabrication, high and uniform surface area coupled with excellent chemical stability, and non-toxic in nature [27-32]. The presence of porous substrate like T-NT has been reported to show remarkable enhancement in the supercapacitance behavior in many composite electrode materials $[3,33]$. The enhancement in capacitance was found to be due to the fact that highly ordered architecture and high surface area of the T-NT substrate facilitated enhanced reaction sites as well as 
improved charge and mass transfer through the tubular tunnels, thus increasing the capacitance of the composite structure. Here, the capacitance properties of the T-NT/CoS composite electrode were studied in the following electrolytes: $\mathrm{KOH}, \mathrm{Na}_{2} \mathrm{SO}_{4}, \mathrm{Na}_{2} \mathrm{SO}_{3}$ and $\mathrm{KCl}$. It is to be noted that the capacitance properties of transition metal sulfide supercapacitors have only been evaluated in $\mathrm{KOH}$ electrolyte so far. An early attempt to study the pseudocapacitance of $\mathrm{CoS}$ in $\mathrm{Na}_{2} \mathrm{SO}_{4}$ electrolyte rendered fruitless as the authors reported very less specific capacitance in this electrolyte [20]. There is a need to explore the applicability of sulfide based supercapacitors in other electrolytes beside $\mathrm{KOH}$. Therefore, we have studied the capacitance of the composite electrode in various other electrolytes using CV, galvanostatic charge-discharge and EIS techniques. These experiments suggested that the composite electrode can attain very high supercapacitance properties in all of the above mentioned electrolytes. The capacitance of the electrode was attributed to a mixed type behavior (ELD + redox) in these electrolytes. Very high specific capacitance and good stability of the electrode material indicated the feasibility of its applicability as supercapacitor in all electrolytes studied here.

\section{Experimental studies}

\subsection{T-NT Substrate Fabrication}

Titantium foil (99.9\% purity) of $0.1 \mathrm{~mm}$ thickness was cut into $10 \mathrm{~mm}$ x $15 \mathrm{~mm}$ coupons. The coupons were roughly polished for $2 \mathrm{~min}$. (with 600 grit $\mathrm{SiC}$ emery paper) and ultrasonically cleaned in a solution of acetone and isopropyl alcohol (1:1) for ten minutes. Subsequently, the coupons were anodized potentiostatically in an electrolyte consisted of ethylene glycol with 0.5 wt $\%$ ammonium fluoride and $10 \% \mathrm{H}_{2} \mathrm{O}$. The anodization was carried out at a constant voltage of $40 \mathrm{~V}$ for 1 hour at room temperature. 
Annealing was performed in a muffle furnace in air at $500^{\circ} \mathrm{C}$. The temperature was raised at a rate of $1.5^{\circ} \mathrm{C} / \mathrm{min}$ to the set point and maintained for 2 hours. After holding the anodized sample at the elevated temperature, the samples were allowed to cool within the furnace by natural convection.

\subsection{Electrochemical Deposition of $\mathrm{CoS}$}

Electrochemical deposition of cobalt sulfide on T-NT surface was carried out in an aqueous solution of $10 \mathrm{mM}$ cobalt chloride $\left(\mathrm{CoCl}_{2} \cdot 6 \mathrm{H}_{2} \mathrm{O}\right)$ and $0.5 \mathrm{M}$ thiourea $\left(\left(\mathrm{NH}_{2}\right)_{2} \mathrm{CS}\right)$. A 3-electrode based electrochemical workstation (Gamry Reference 600) with annealed T-NT coupon as working electrode, platinum coil as counter electrode and a saturated $\mathrm{Ag} / \mathrm{AgCl}$ electrode as reference constituted the electrochemical deposition setup. Electronic noise was minimized by isolating the system within a Faraday cage. Potentiostatic depositions were carried out at two different potentials of $-0.5 \mathrm{~V}$ to $-1.5 \mathrm{~V}$. CV deposition was performed by cyclically varying the potential between $-0.5 \mathrm{~V}$ to $-1.5 \mathrm{~V}$ for 10 cycles at a scan rate of $20 \mathrm{mV} \mathrm{s}^{-1}$. The deposition bath was constantly stirred at $170 \mathrm{rpm}$ during experiments. Electrochemical deposition was performed at standard conditions.

\subsection{Characterization}

Examination of the surface and cross sectional morphology of T-NT and T-NT/CoS samples was performed using a field emission scanning electron microscope (FE-SEM, Hitachi S-4800). The XRD analysis of the samples was carried out using SIEMENS D5000 diffractometer with copper K- $\alpha$ radiation. The diffraction tests were done by $\theta$ to $\theta$ scan from $20^{\circ}$ to $80^{\circ}$. X-ray photoelectron spectroscopy (XPS) study was carried out using monochromatic Al Ka source (PE $=1600 \mathrm{eV}$ ) on a Kratos Axis Ultra DLD instrument, with a $300-700 \mu \mathrm{m}$ spot size. Dwell time was set to $200 \mathrm{~ms}$ with three sweeps and a step size of $1 \mathrm{eV}(0.1 \mathrm{eV}$ for regional scans).The 
weight of the deposited $\mathrm{CoS}$ was determined using a Satorius microbalance with the accuracy of $0.01 \mathrm{mg}$. The mass of the deposited $\mathrm{CoS}$ was determined as follows: The initial weight $\left(m_{1}\right)$ of the T-NT was measured after annealing. Then, after deposition of CoS on to the T-NT substrate, the composite electrode was dried at $110^{\circ} \mathrm{C}$ for 2 hours and the weight $\left(m_{2}\right)$ of the composite electrode was measured. By subtracting $m_{1}$ from $m_{2}$, the weight of the deposited CoS was obtained.

\subsection{Electrochemical Measurements}

The electrochemical properties of the T-NT/CoS samples were evaluated by conducting cyclic voltammetry (CV) and galvanostatic charge-discharge experiments using a potentiostat (Gamry Reference 600), connected to a 3-electrode setup consisting of the T-NT/CoS sample as the working electrode, platinum coil as the counter electrode, and saturated $\mathrm{Ag} / \mathrm{AgCl}$ electrode as a reference electrode. $\mathrm{CV}$ tests were performed in $2 \mathrm{M} \mathrm{KOH}, 2 \mathrm{M} \mathrm{KCl}, 1 \mathrm{M} \mathrm{Na}_{2} \mathrm{SO}_{3}$ and $1 \mathrm{M} \mathrm{Na}_{2} \mathrm{SO}_{4}$ electrolytes. Galvanostatic charge/discharge tests were performed in $2 \mathrm{M} \mathrm{KCl}, 1 \mathrm{M} \mathrm{Na} 2 \mathrm{SO}_{3}$ and $1 \mathrm{M} \mathrm{Na}_{2} \mathrm{SO}_{4}$ electrolytes. Potentiostatic EIS tests were carried out using a Parstat 4000 (Applied Princeton Research) at $-0.5 \mathrm{~V}$ (vs reference) with perturbation amplitude of $10 \mathrm{mV}$ in the frequency range of $100 \mathrm{~Hz}$ to $25 \mathrm{mHz}$. Prior to the EIS measurements, the electrodes were equilibrated with the electrolyte for 30 minutes.

\section{Results and Discussion}

\subsection{Morphology and Phase of T-NT/CoS:}

Figure 1 shows the self-organized and vertically aligned T-NT array formed on the titanium foil after anodization at $40 \mathrm{~V}$ for $1 \mathrm{hr}$. The nanotubes were found to have an average diameter of $\sim 90$ $\mathrm{nm}$, length of $\sim 1.5 \mu \mathrm{m}$ (inset Fig. 1) and wall thicknesses in the range of $15-20 \mathrm{~nm}$. 
Prior to deposition, $\mathrm{CV}$ analysis was carried out in an aqueous solution of $10 \mathrm{mM}$ cobalt chloride and $0.5 \mathrm{M}$ thiourea to establish suitable deposition parameters. The CV profile was recorded at $20 \mathrm{mV} \mathrm{s}^{-1}$ scan rate between +1.5 to $-2.0 \mathrm{~V}$ vs $\mathrm{Ag} / \mathrm{AgCl}$ reference electrode as shown in Figure 2. From the plot, the deposition of the cobalt sulfide phase appeared to start at a potential close to $0.5 \mathrm{~V}$, while the deposition might as well continue up to $-2.0 \mathrm{~V}$ of the reference electrode.

The following reactions could be attributed for the deposition process [34]:

$\mathrm{CoCl}_{2}=\mathrm{Co}^{2+}+2 \mathrm{Cl}^{-}$

$\left(\mathrm{NH}_{2}\right)_{2} \mathrm{CS}+\mathrm{OH}^{-}=\mathrm{CH}_{2} \mathrm{~N}_{2}+\mathrm{H}_{2} \mathrm{O}+\mathrm{HS}^{-}$

$\mathrm{HS}^{-}+\mathrm{OH}^{-}=\mathrm{H}_{2} \mathrm{O}+\mathrm{S}^{-}$

$\mathrm{Co}^{2+}+\mathrm{S}^{-}=\mathrm{CoS}$

Based on the $\mathrm{CV}$ analysis, we have carried out both potentiostatic and cyclic voltametric deposition to see the effect of the deposition parameters on the morphology of the CoS phase. Generally, it has been emphasized that relatively more porous structure can be achieved through $\mathrm{CV}$ deposition compared to the potentiostatic and potentiodynamic deposition processes [35]. To investigate this, the potentiostatic depositions were carried out at $-0.5 \mathrm{~V}$ and $-1.5 \mathrm{~V}$, and the $\mathrm{CV}$ deposition was conducted by cyclically varying the potentials between these two potential limits. The deposition time was kept the same in all deposition conditions (16 min).

Figure 3 shows the morphology of the deposited CoS layer on T-NT substrate under various deposition conditions. The CoS layer appeared to non-uniform after deposition at $-0.5 \mathrm{~V}$ (Fig. 3a) may be due to the fact that this potential is close to the onset potential for deposition as observed in the prior CV study (Fig. 2). On the other hand, when deposition was performed at $1.5 \mathrm{~V}$, the sulfide layer appeared to be very dense (Fig. $3 \mathrm{~b}$ ) in comparison to the one observed at - 
0.5V. However, after the CV deposition, the layer appeared to be much uniform than that obtained at $-0.5 \mathrm{~V}$ and relatively more porous compared to the one achieved after deposition at $1.5 \mathrm{~V}$ (Fig 3c). Therefore, further analysis and electrochemical tests were performed on the sample obtained through the $\mathrm{CV}$ deposition technique and for more clarity, this sample will be referred to as "T-NT/CoS electrode" in further discussions. It is to be noted that the CoS phase did not penetrate through the titania nanotubes during the deposition process. For example after deposition at $-0.5 \mathrm{~V}$, the inside of the nanotube pores appeared to be devoid of any CoS phase (Fig 3a). However, deposition at $-1.5 \mathrm{~V}$ and the $\mathrm{CV}$ deposition resulted in formation of CoS nanoparticles decorating the rims of the nanotubes as shown in Figure 3(d\&e). Notice that still there is no penetration of $\mathrm{CoS}$ particles in the pores at these deposition conditions. The weight of the cobalt sulfide deposit in the T-NT/CoS electrode was found to be approximately $0.15 \mathrm{mg} \mathrm{cm}^{-2}$.

The XRD profile obtained for the T-NT/CoS electrode is shown in Figure 4. The peaks from the (220) and (330) planes of the CoS phase thus indicate the formation of crystalline phase of the deposited sulfide. Also these peaks reveal that the CoS phase is hexagonal in nature consistent with previous reported studies (JCPDS no. 19-366) [17, 18]. Please note that some of the peaks from the anatase phase of the T-NT a as well as Ti-substrate can also be observed in the XRD profile. Further, the oxidation states of $\mathrm{Co}$ and $\mathrm{S}$ in the deposited sulfide phase were investigated by conducting XPS analysis on the T-NT/CoS electrode. High resolution XPS spectra of Co 2p, and $S 2 p$ peaks are presented in Figure 5(a\&b). The Co $2 p$ spectrum, shown in Figure 5a, contains a main peak located at a binding energy value of $779.8 \mathrm{eV}$ and a shake-up feature at higher binding energy. These peaks can be assigned to $\mathrm{Co}^{2+}$ of $\mathrm{CoS}$ phase as supported by the literature [36-39]. Further, the Co-spectrum can be de-convoluted into couple of more constituent components corresponding to the following chemical states: $\mathrm{CoO}$ and $\mathrm{Co}(\mathrm{OH})_{2}$. The presence of 
$\mathrm{CoO}$ is also attributed due to the presence of signal at $780 \mathrm{eV}$. The $2 \mathrm{p}_{3 / 2}$ peak observed at 786.1 $\mathrm{eV}$ can be attributed to a shake-up satellite of $\mathrm{CoO}$ [40]. It has been suggested in many studies that electrodeposition of transition metal based oxide or sulfide phases often results in coexistence of many of these species $\left(\mathrm{CoO}, \mathrm{Co}(\mathrm{OH})_{2}, \mathrm{Co}, \mathrm{CoOOH}\right.$ etc) in the deposited layer [41, 42]. Figure $5 b$ shows that the binding energy value of $S 2 p$ is around $162 \mathrm{eV}$, indicating that most of the S species exist as $\mathrm{S}^{2-}$. Therefore, the XPS analysis indicated the deposited layer to be consisted of mostly CoS phase.

\subsection{Pseudocapacitance of T-NT/CoS in KOH Electrolyte:}

The supercapacitance behavior of the T-NT/CoS electrode was first evaluated using cyclic voltammetric studies in $2 \mathrm{M} \mathrm{KOH}$ electrolyte. The $\mathrm{CV}$ profiles, recorded at various scan rates (20 to $500 \mathrm{mVs}^{-1}$ ) within a potential window of $-0.2 \mathrm{~V}$ to $0.6 \mathrm{~V}$ are presented in Figure 6a. With increase in scan rate, the area under CV curve increases. This is concomitant with the increase in the current response in the CV profiles with increase in scan rate. Further, the shape of the CV curves did not display the conventional electric double-layer capacitance behavior as these profiles deviated from the ideal rectangular shape. In these plots, indications of redox processes are evident, suggesting that the capacitance mainly resulted from the redox reactions between the electrode and the electrolyte. These redox peaks are rather broad and shallow. However, at a very

slow scan rate $\left(1 \mathrm{mV} \mathrm{s}^{-1}\right)$, the redox peaks became very evident (Inset of Fig. 6a). It was suggested [16] that the redox peak potentials of $\mathrm{CoS}$ are very close to those of $\mathrm{Co}(\mathrm{OH})_{2}$ and the electron transfer process of $\mathrm{CoS}$ in alkaline media should take place between different valence states of cobalt, such as $\mathrm{Co}^{2+}, \mathrm{Co}^{3+}$ and $\mathrm{Co}^{4+}$. Further, both sulfur and oxygen belong to the same group. In this case also, anodic peaks, marked as Oxidation 1 and Oxidation 2 in inset of Figure 6a, are believed to be because of the oxidation of $\mathrm{CoS}$ to $\mathrm{CoSOH}$ and $\mathrm{CoSOH}$ to $\mathrm{CoSO}$, 
respectively, as argued previously [16, 20]. The cathodic peaks (Reduction 1 and Reduction 2, inset of Fig. 6a) are assumed to be due to the reverse processes occurring at the CoS electrode as shown in the reactions below [16, 20],

$\mathrm{CoS}+\mathrm{OH}^{-}=\mathrm{CoSOH}+\mathrm{H}_{2} \mathrm{O}+\mathrm{e}^{-}$

$\mathrm{CoSOH}+\mathrm{OH}^{-}=\mathrm{CoSO}+\mathrm{H}_{2} \mathrm{O}+\mathrm{e}^{-}$

The anodic-cathodic reverse processes are the characteristic signatures of the pseudo capacitance behavior of CoS electrode as observed in many other research work [16, 20]. Further, the overall shape of the CV curve did not change with increase in the scan rate suggesting a good capacitance behavior of the electrode material.

Based on the CV results, the specific capacitance $(C)$ of the T-NT/CoS electrode was calculated as the function of the scan rate using Eqn. 7 (shown below) and presented in Figure 6b.

$C=Q / \Delta V m$

Where $Q=$ half of the total charge from the integrated $\mathrm{CV}$ area, $\Delta V=$ Voltage window, $m=$ mass of CoS deposit.

Usually, reduction in specific capacitance is observed at higher scan rates [3], a normal trend associated with the higher resistance and circuitous diffusion tracks of the porous electrode material. At a lower scan rates, the entire electrode material (both outer and inner pore surfaces) is utilized for charge migration, while at higher scan rates only outer regions of the electrode can be accessed by the electrolyte. Therefore, as shown in Figure 6b, the specific capacitance of the composite electrode decreased by $45 \%$ at the scan rate of $500 \mathrm{mV} \mathrm{s}^{-1}$ compared to the value at 20 $\mathrm{mV} \mathrm{s}^{-1}$ 
Repetitive CV experiments were conducted on the composite electrode a scan rate of $300 \mathrm{mV} \mathrm{s}^{-1}$ for up to a total of 300 cycles. The comparative $\mathrm{CV}$ profiles after $1^{\text {st }}$ and $300^{\text {th }}$ cycles are shown in Figure 6c. The CV profiles appeared nearly the same with remarkable shape and area retention suggesting that the depletion of capacitance was insignificant even after a large number of $\mathrm{CV}$ cycles. Therefore, it is a clear demonstration of the excellent cyclic stability and superior capacitance behavior of the electrode material.

The surface morphology of the T-NT/CoS electrode was analyzed after undergoing 300 cycles of $\mathrm{CV}$ in the $\mathrm{KOH}$ electrolyte. A shown in Figure 7, the morphology of the CoS deposit underwent drastic change from a porous layer (as observed in the as-deposited condition, Fig. 3c) to a platelet like morphology after the CV cycles (Fig. 7). The inset in Figure 7 showed that the thickness of the platelet was about $80 \mathrm{~nm}$. The XPS data for the Co $2 \mathrm{p}$, and S $2 \mathrm{p}$ spectra were also obtained for the electrode after the repetitive CV cycling and presented in Figure S1 (Supp. Info.). The presence of peaks at $779.8 \mathrm{eV}$ and a shake-up feature at higher binding energies for $\mathrm{Co}^{2+}$ and peak at around $162 \mathrm{eV}$ for $\mathrm{S}^{2-}$ are indicative of the presence of $\mathrm{CoS}$ phase. These peaks and their positions are similar to that of the as deposited condition (Fig. 5) suggesting that although the shape/morphology of the sulfide phase changed, the crystal phase remained unchanged after the CV experiments.

\subsection{Pseudocapacitance of T-NT/CoS in $\mathrm{KCl}, \mathrm{Na}_{2} \mathrm{SO}_{4}$ and $\mathrm{Na}_{2} \mathrm{SO}_{3}$ Electrolytes:}

The supercapacitance behavior of the T-NT/CoS electrode has also been studied in three other electrolytes: $1 \mathrm{M} \mathrm{Na}_{2} \mathrm{SO}_{4}, 1 \mathrm{M} \mathrm{Na} 2 \mathrm{SO}_{3}$ and $2 \mathrm{M} \mathrm{KCl}$. The $\mathrm{CV}$ experiments were performed in the same potential window of -1.0 to $0 \mathrm{~V}$ in all the above electrolytes. The resultant $\mathrm{CV}$ profiles recoded at various scan rates of $20-500 \mathrm{mV} \mathrm{s}^{-1}$ are presented in Figure $8(\mathrm{a}-\mathrm{c})$. Irrespective of the 
electrolyte, it can clearly be observed from these profiles that the capacitive nature of the TNT/CoS electrode is a mixture of both EDL as well as pseudo-behavior. The curves appeared to have indications of cathodic and anodic redox peaks suggesting the influence of pseudo nature in the overall capacitance behavior of the electrode (the inset figures shows the CV profiles obtained at $1 \mathrm{mV} \mathrm{s}^{-1}$ - demonstrating clearly the redox-humps). It is worth noting here that $\mathrm{CV}$ studies of many cobalt sulfide supercapacitor electrodes demonstrated rather broad redox peaks $[17,20,43-45]$. Although the specific reasons for such behavior has not been communicated yet, one possibility could be the co-existence of various phase in the deposit as observed in the XPS analysis (Fig 5a). Nevertheless, in all electrolytes, the cathodic peaks were observed between 0.8 to $-0.6 \mathrm{~V}$, while the anodic peaks were present between -0.6 to $-0.4 \mathrm{~V}$. There was an increase in current values in the $\mathrm{CV}$ curves with increase in scan rate. Also, the sharp change in current at each terminal potential of the $\mathrm{CV}$ profile is also concomitant with the pseudo capacitance behavior of electrode material. Further, the shape of the CV curves did not change with increase in the scan rate in all electrolytes demonstrating an excellent pseudocapacititive response of the electrode material. A brief comparison of shape/size of CV profiles (Fig. 8d) indicated that they are rather similar for the cases of $\mathrm{Na}_{2} \mathrm{SO}_{4}$ and $\mathrm{KCl}$ electrolytes; however a slight variation was observed in the case of $\mathrm{Na}_{2} \mathrm{SO}_{3}$ electrolyte. For instance, the area under the $\mathrm{CV}$ curves was slightly smaller in the former electrolytes compared to the later one (Fig. 8a). Also the redox peaks in the $\mathrm{Na}_{2} \mathrm{SO}_{3}$ electrolyte were relatively sharper. The maxima of the redox peaks are observed around $-0.7 \mathrm{~V}$ in the $\mathrm{Na}_{2} \mathrm{SO}_{3}$ electrolyte. Therefore, it appears that the specific capacitance of the electrode in $\mathrm{Na}_{2} \mathrm{SO}_{3}$ electrolyte was relatively higher. In order to demonstrate the enhancement in capacitance of the T-NT/CoS electrode due to the presence of the porous TNT substrate along with the electro-active CoS phase, CV experiments were also carried out 
using Ti/CoS electrode as well as bare T-NT electrode (no CoS phase). The comparative CV studies, presented in Figure S2 (Supporting Information), demonstrates clearly the enhancement due to the presence of the T-NT substrate in the T-NT/CoS electrode.

Figure 9a shows the variations in anodic peak current values from the CV curves (Fig. 8) obtained in these electrolytes plotted as the function of the scan rate. The anodic current values demonstrated linear relationship in all electrolytes corroborating the occurrence of surface redox reactions and the pseudocapacitance nature of $\mathrm{CoS}$ electrode [46]. The CV profiles also show that the change in peak current positions is rather small with increase in scan rates. The linear relationship of peak current with scan rate as well as small shifts in peak potentials suggested good rate capabilities and excellent reversibility of the electrode in these electrolytes [46].

Figure $9 \mathrm{~b}$ shows the specific capacitance (calculated using Eqn. 7) of the T-NT/CoS electrode at various scan rates obtained in these electrolytes. The figure shows decrease in the specific capacitance with increase in scan rate. The decreasing trend of capacitance in the case of electrochemical capacitor is very common and the reason for such has been discussed above. In short, it can be attributed to the non-accessible inner active sites in the T-NT/CoS electrode by the electrolytic ions at higher scan rate due to diffusion limitations. Therefore, a complete redox transition is not achieved at higher scan rate, leading to a decrease in the specific capacitance. However, the specific capacitance obtained in the $\mathrm{Na}_{2} \mathrm{SO}_{3}$ electrolyte was highest among the three electrolytes, while it was least in the $\mathrm{Na}_{2} \mathrm{SO}_{4}$ electrolyte. For example, there was nearly $30 \%$ increase in specific capacitance in $\mathrm{Na}_{2} \mathrm{SO}_{3}$ electrolyte compared to that of $\mathrm{Na}_{2} \mathrm{SO}_{4}$ at the scan rate of $20 \mathrm{mV} \mathrm{s}^{-1}$ (Fig. 9b). 
The electrochemical capacitance of the T-NT/CoS electrode is appeared to be more dependent on the type of anions $\left(\mathrm{SO}_{3}{ }^{2-}, \mathrm{SO}_{4}{ }^{2-}, \mathrm{Cl}^{-}\right)$present in the electrolyte compared to the cations $\left(\mathrm{K}^{+}, \mathrm{Na}^{+}\right.$ etc). Similar behavior of anion-dependent supecapacitance properties has been also observed in case of magnetite/carbon-black composite electrode [47]. In their study, they have witnessed that the specific capacitance of the electrode was highest in the $\mathrm{Na}_{2} \mathrm{SO}_{3}$ compared to $\mathrm{Na}_{2} \mathrm{SO}_{4}$ and $\mathrm{NaCl}$ electrolytes partly due to enhanced redox activities between the electrode and the $\mathrm{SO}_{3}{ }^{2-}$ species of the former electrolyte. They explained their findings based on the rest potentials and the anion concentrations in the electrolyte - for example, the enhanced pseudo-behavior in the $\mathrm{Na}_{2} \mathrm{SO}_{3}$ electrolyte was due to stronger dependence of rest potentials on the concentration of anions in the solution. Similar argument may also prevail in this case as the dependence of the specific capacitance of the T-NT/CoS electrode appeared to have followed similar pattern as observed in their work.

The stability of the composite electrode in different electrolytes have been evaluated by employing consecutive CV up to 300 cycles at a scan rate of $100 \mathrm{mV} \mathrm{s}^{-1}$. Figure 10 (a-c) shows the comparative $\mathrm{CV}$ profiles of T-NT/CoS electrode in $\mathrm{Na}_{2} \mathrm{SO}_{4}, \mathrm{Na}_{2} \mathrm{SO}_{3}$ and $\mathrm{KCl}$ electrolytes after $1^{\text {st }}, 100^{\text {th }}$ and $300^{\text {th }} \mathrm{CV}$ cycles. In all electrolytes, the redox peaks were clearly observed even after $300^{\text {th }} \mathrm{CV}$ cycle indicating sustained redox-based reactions between the electrode/electrolyte systems. The CV plots indicate decrease in specific capacitance of the T$\mathrm{NT} / \mathrm{CoS}$ electrode with increase in number of CV cycles. The decrease in current response with number of cycles is slightly higher in $\mathrm{Na}_{2} \mathrm{SO}_{4}$ electrolyte, compared to $\mathrm{Na}_{2} \mathrm{SO}_{3}$ and $\mathrm{KCl}$ electrolytes. Up to $100^{\text {th }} \mathrm{CV}$ cycle, there has been some decrease in current response in all electrolytes; however the current level remained unchanged afterwards. The CV profiles after the $100^{\text {th }}$ and the $300^{\text {th }}$ cycles appeared to be nearly the same in all electrolytes. Therefore, it can be 
observed that substantial amount of capacitance was retained even after large number of CV cycles in all electrolytes.

To study the integrity of the T-NT/CoS electrode after undergoing consecutive CV cycles, the microstructural and compositional analysis of the electrode was carried out by SEM and XPS analysis, respectively. Figure 11 shows the SEM images of the electrode after the repetitive CV experiments. The micrographs suggested that the morphological aspects of the CoS deposit did not change to any significant degree after the repetitive $\mathrm{CV}$ cycles. In fact, the $\mathrm{CoS}$ phase deposit appeared to be foamy and porous similar to that observed in the as-deposited condition (Fig. 2a). The compositional analysis also suggested remarkable stability of the electrode after the CV studies. Figure S3 (Supp. Info.) shows the XPS spectra for Co $2 p$, and S $2 p$ obtained for the electrode after the repetitive $\mathrm{CV}$ in various electrolytes. The positions of the peaks for Co $2 p$, and S 2p suggested that the phase composition of the sulfide phase was unaltered in comparison to Figure 3, suggesting excellent stability of the electrode material.

The galvanostatic charge-discharge behavior of T-NT/CoS electrode was evaluated in the $\mathrm{Na}_{2} \mathrm{SO}_{4}, \mathrm{Na}_{2} \mathrm{SO}_{3}$ and $\mathrm{KCl}$ electrolytes at constant current densities of 1,3 and $5 \mathrm{~mA} \mathrm{~cm}$ in the voltage window of 0 to $-1 \mathrm{~V}$. Figure 12 (a-c) shows the charge-discharge profiles for the electrode in these electrolytes. The profiles, in terms of voltage-time (V-t), appeared to be nonsymmetric. However, in all the electrolytes, the shape of the charge-discharge profiles appears to be similar. Specially, the discharge curves consisted of two parts: (i) a steep voltage drop due to the internal resistance and (ii) a relatively curved part with gradual decrease in voltage due to the change in energy within the capacitor. Furthermore, charge-discharge time decreased with 
increase in current density. Using the following relationship, the specific capacitance of the electrode materials was calculated as:

$C=I t / \Delta V m$

where, $I$ is the charge-discharge current density, $t$ is the discharge time from the $V$ - $t$ plots, $\Delta V$ is the voltage window, $m$ is the mass of the electrode. The calculated specific capacitance of the electrodes in various electrolytes were plotted as the function of the charge-discharge current density and shown in of Figure 12d .The specific capacitance decreased by about 20-27\% in all electrolytes upon increase in charge-discharge current density. Specifically, the capacitance of the electrode in the $\mathrm{Na}_{2} \mathrm{SO}_{3}$ electrolyte decreased from $487 \mathrm{~F} \mathrm{~g}^{-1}$ to $389 \mathrm{~F} \mathrm{~g}^{-1}$ upon increase in current density from 1 to $5 \mathrm{~mA} \mathrm{~cm}{ }^{-2}$. Similar trend was also observed in the other two electrolytes. These results are in strong agreement with the CV analysis in these electrolytes (Fig. 8).

The stability of the electrode was also evaluated by imposing continuous charge-discharge cycles up to 1000 cycles in the three electrolytes at a charge-discharge current density of $5 \mathrm{~mA} \mathrm{~cm}^{-2}$. Figure 13a shows the variations in specific capacitance of the electrode as the function of cycle number in various electrolytes. The inset figure shows the representative charge-discharge curves $(\mathrm{V}-\mathrm{t})$ for the electrode during the beginning of the charge-discharge experiment in various electrolytes. Consistent with the CV results (Fig. 10), the capacitance behavior of the electrode was found to be very stable even after a large number of charge-discharge cycles. The specific capacitance was highest in the $\mathrm{Na}_{2} \mathrm{SO}_{3}$ electrolyte among all electrolytes investigated in this study. On the other hand, only about $20 \%$ of the capacitance faded after the 1000 cycle irrespective of the electrolyte used. This decrease in capacitance could be attributed to the small 
dissolution of the electroactive material $(\mathrm{CoS})$ in to the electrolytes [25]. Figure $13(\mathrm{~b}-\mathrm{d})$ shows the charge-discharge cycles of the electrode after the end of 1000 cycles in various electrolytes.

A brief comparison of the capacitance of the T-NT/CoS electrode can be made with some of the literature reported values for $\mathrm{CoS}$ electrodes. Justin et al [16] reported that their porous spherelike $\mathrm{CoS}$ electrode demonstrated low charge-transfer resistance and good reversibility with a specific capacitance of $363 \mathrm{~F} \mathrm{~g}^{-1}$. Wang and co-workers [18] also observed high specific capacitance $\left(555 \mathrm{~F} \mathrm{~g}^{-1}\right.$ ) in their flower-liked nanostructured $\mathrm{CoS}_{1.097}$ electrode along with excellent cycle stability. In another study, supercapacitor electrode comprising of hollow $\mathrm{Co}_{3} \mathrm{~S}_{4}$ nanospheres on reduced graphene oxide substrate showed a specific capacitance of $521 \mathrm{~F} \mathrm{~g}^{-1}$ with very high Columbic efficiency [19]. Tao et al. [20] reported capacitance behavior of microsized $\mathrm{CoS}_{\mathrm{x}}$ using $6 \mathrm{M} \mathrm{KOH}$ electrolyte and obtained a high value of specific capacitance (475 F $\left.\mathrm{g}^{-1}\right)$. In comparison to these studies, it is evident that that overall capacitance property of the TNT/CoS electrode observed in this study is at par with many of the earlier literature reported values. Hence, the feasibility of using T-NT/CoS composite electrode in these electrolytes is quite viable as demonstrated successfully through this study.

\subsection{EIS study of T-NT/CoS electrode:}

Figure 14 shows the Nyquist plot for the T-NT/CoS electrode in various electrolytes. All EIS profiles show capacitance arc/depressed semicircle at high frequency domain and a linear curve at lower frequencies as observed in these plots. The semicircular profiles indicate that irrespective of the electrolytes, there is some amount of interfacial charge transfer resistance between the electrode/electrolyte systems. This behavior has also been observed in the case of CoS electrode in earlier studies $[16,17]$. Further, it has also been suggested that a vertical line in the Nyquist plot leaning towards the imaginary axis suggests EDL type capacitance behavior 
[16,17,42]. However, in our case, the EIS profiles (Fig. 14a\&b) showed considerable deviations from the imaginary axis in all electrolytes. This represents the ionic diffusion into the pores of the electrode suggesting the capacitive nature of the electrode in these electrolytes. These observations are also supported well by the CV and charge-discharge results discussed in the previous sections. Therefore, higher conductivity and reduced charge transfer resistance observed in the EIS studies support the higher capacitive performance obtained in the T-NT/CoS composite electrode.

\section{Conclusion}

In this study, we have demonstrated a simple and economical electrodeposition process (potentiostatic and $\mathrm{CV}$ depositions) to synthesize titania nanotubes (T-NT)/CoS composite material for supercapacitance applications. The morphology and phases of CoS deposit were analyzed using various characterization tools, such as SEM, XRD, and XPS. The electrochemical tests on the composite materials were carried out in four different electrolytes: $2 \mathrm{M} \mathrm{KOH}, 1 \mathrm{M}$ $\mathrm{Na}_{2} \mathrm{SO}_{4}, 1 \mathrm{M} \mathrm{Na} \mathrm{SO}_{3}$ and $2 \mathrm{M} \mathrm{KCl}$ using a three electrode experimental set-up. More emphasis was given on the supercapacitance studies in the $1 \mathrm{M} \mathrm{Na} 2 \mathrm{SO}_{4}, 1 \mathrm{M} \mathrm{Na} \mathrm{SO}_{3}$ and $2 \mathrm{M} \mathrm{KCl}$ electrolytes as transition metal sulfide based supercapacitors have never been studied in these electrolytes. The $\mathrm{CV}$ analysis indicated that the capacitance of the composite electrode emanated partly from the fast and reversible faradic-redox reactions occurring in the electrode/electrolyte interface in all electrolytes. From the CV studies, the highest specific capacitance values achieved were about $493,427,374$, and $360 \mathrm{~F} \mathrm{~g}^{-1}$ for the $\mathrm{Na}_{2} \mathrm{SO}_{3}, \mathrm{KCl}, \mathrm{Na}_{2} \mathrm{SO}_{4}$, and $\mathrm{KOH}$ electrolytes, respectively. The galvanostatic charge-discharge experiments were also carried out on the composite electrode in the $1 \mathrm{M} \mathrm{Na}_{2} \mathrm{SO}_{4}, 1 \mathrm{M} \mathrm{Na}_{2} \mathrm{SO}_{3}$ and $2 \mathrm{M} \mathrm{KCl}$ electrolytes. The results 
in fact reinforced the findings of the $\mathrm{CV}$ analysis, suggesting that the specific capacitance of the composite materials can reach very high value in all electrolytes. The galvanostatic chargedischarge experiments also resulted in the maximum specific capacitance in the range of 450-500 $\mathrm{F} \mathrm{g}^{-1}$ for all electrolytes. This high capacitance for the electrode was attributed to the combined effect of the redox reactions associated with the $\operatorname{CoS}$ in the electrolytes as well as the high surface area associated with the nanotubular nature of the substrate material. The stability of the composite material was also evaluated by employing continuous charge-discharge cycle up to 1000 cycles. A very high percentage $(\sim 80 \%)$ of capacitance retention was achieved in the composite material even after successive charge-discharge cycles. Therefore, this study successfully demonstrated the feasibility of T-NT/CoS electrode to be used as high performance supercapacitor material in various electrolytes.

\section{Acknowledgement}

The authors acknowledge U.S. Department of Energy (DE-FC-36-06GO86066) for the financial support supported to carry out the work presented here. 


\section{References}

1. Burke A. Ultracapacitors: why, how, and where is the technology. J Power Sources. 91 (2000) $37-50$

2. P. Simon YG. Materials for Electrochemical Capacitors. Nat Mater. 7 (2008) 845-54.

3. B. Sarma YS, A.L. Jurovirtski, S. Mohanty, M. Misra, Redox-Induced Enhancement in Interfacial Capacitance of the Titania Nanotube/Bismuth Oxide Composite Electrode, Appl Mater Inter. 5 (2013) 1688-97

4. C.D. Lokhande, D.P. Dubal, Oh-Shim Joo, Metal oxide thin film based supercapacitors, Current Applied Physics. 11 (2011) 255-170

5. Y. Zhang, H. Feng, X. Wu, L. Wang, A. Zhang, T. Xia, H. Dong, X. Li, L. Zhang, Progress of electrochemical capacitor electrode materials: A review, Int. J Hydrogen Energy 34 (2009) 4889-4899

6. C.C. Hu WCC, K.H. Chang, How to Achieve Maximum Utilization of Hydrous Ruthenium Oxide for Supercapacitors, J Electrochem Soc. 151 (2004) A281-A90.

7. J. Jiang, A. Kucernak, Electrochemical supercapacitor material based on manganese oxide: preparation and characterization, Electrochim. Acta. 47 (2002) 2381-2386

8. Z. Yang, F. Xu, W. Zhang, Z. Mei, B. Pei, X. Zhu, Controllable preparation of multishelled NiO hollow nanospheres via layer-by-layer self-assembly for supercapacitor application, J. Power Sources. 246 (2014) 24-31

9. J. H. Kwak, Y.-W. Lee, J. H. Bang, Supercapacitor electrode with an ultrahigh Co3O4 loading for a high areal capacitance, Mater Lett. 110 (2013) 237-240

10. B. Sarma, R. S. Ray, S.K. Mohanty, M. Misra, Synergistic Enhancement in the Capacitance of Nickel and Cobalt Based Mixed Oxide Supercapacitor Prepared by Electrodeposition, Applied Surface Science. 300 (2014) 29-36

11. B. M. Sánchez, T. Brousse, C. R. Castro, V. Nicolosi, P. S. Grant, An investigation of nanostructured thin film $\alpha-\mathrm{MoO} 3$ based supercapacitor electrodes in an aqueous electrolyte, Electrochim. Acta, 91 (2013) 253-260

12. J. Shao, X. Li, Q. Qu, H. Zheng, One-step hydrothermal synthesis of hexangular starfruit-like vanadium oxide for high power aqueous supercapacitors, J. Power Sources, 219 (2012) 253-257

13. P.M. Kulal DPD, C.D. Lokhande, V.J. Fulari, Chemical synthesis of Fe $2 \mathrm{O} 3$ thin films for supercapacitor application, J Alloy compd. 509 (2011) 2567-71.

14. B. Sarma Y. Smith, A. L. Jurovitzki, R. S. Ray, S. K. Mohanty, M. Misra, Supercapacitance behavior of porous oxide layer grown on 302 type stainless steel substrate, J Power Sources. 236 (2013) 103-11. 
15. L. Zhang, H. B. Wu, X. W. Lou, Unusual CoS2 ellipsoids with anisotropic tube-like cavities and their application in supercapacitors, Chem. Commun. 48 (2012) 6912-6914

16. P. Justin, G. R. Rao, CoS spheres for high-rate electrochemical capacitive energy storage application, Int. J. Hydrogen Energy, 35 (2010) 9709-9715

17. S. J. Bao, C. M. Li, C. X. Guo, Y. Qiao, Biomolecule-assisted synthesis of cobalt sulfide nanowires for application in supercapacitors, J. Power Sources, 180 (2008) 676-681

18. Q. Wang, L. Jiao, H. Du, J. Yang, Q. Huan, W. Peng, Y. Si, Y. Wang, H. Yuan, Facile synthesis and superior supercapacitor performances of three-dimensional cobalt sulfide hierarchitectures, CrystEngComm, 13 (2011) 6960

19. Q. Wang, L. Jiao, H. Du, W. Peng, Y. Han, D. Song, Y. Si, Y. Wang, H. Yuan, Novel flower-like CoS hierarchitectures: one-pot synthesis and electrochemical properties. J Mater. Chem., 21 (2011) 327-329

20. F. Tao, Y. Q. Zhao, G. Q. Zhang, H. L. Li, Electrochemical characterization on cobalt sulfide for electrochemical supercapacitors, Electrochem. Commun., 9 (2007) 1282-1287

21. Z. Yang, C. Y. Chen, H. T. Chang, Supercapacitors incorporating hollow cobalt sulfide hexagonal nanosheets, J. Power Sources, 196 (2011) 7874- 7877

22. Q. Wang, L. Jiao, H. Du, Y. Si, Y. Wang, H. Yuan, Co3S4 hollow nanospheres grown on graphene as advanced electrode materials for supercapacitors, J. Mater. Chem., 22 (2012) 21387

23. C. Y. Chen, Z. Y. Shih, Z. Yang, H. T. Chang, Carbon nanotubes/cobalt sulfide composites as potential high-rate and high-efficiency supercapacitors, J. Power Sources, 215 (2012) 43-47

24. J. Pu, Z. Wang, K. Wu, N. Yu, E. Shenga, Co9S8 nanotube arrays supported on nickel foam for high-performance supercapacitors, Phys. Chem. Chem. Phys., 16 (2014) 785-791

25. A. Wang, H. Wang, S. Zhang, C. Mao, J. Song, H. Niu, B. Jin, Y. Tian, Controlled synthesis of nickel sulfide/graphene oxide nanocomposite for high-performance supercapacitor, Appl. Surf. Sci., 282 (2013) 704-708

26. S. W. Chou, J. Y. Lin, Cathodic Deposition of Flaky Nickel Sulfide Nanostructure as an Electroactive Material for High-Performance Supercapacitors, J. Electrochem. Soc. 160 (2013) D178-D182

27. Y. Smith, B. Sarma, S. Mohanty, M. Misra, Formation of TiO2-WO3 nanotubular composite via single-step anodization and its application in photoelectrochemical hydrogen generation, Electrochemistry Communications, 19 (2012) 131-134

28. Y. Smith, B. Sarma, S. Mohanty, M. Misra, Light-Assisted Anodized TiO2 Nanotube Arrays, ACS, Applied Materials \& Interfaces, 4 (2012) 5883-5890

29. Y. Smith, B. Sarma, S. Mohanty, M. Misra, Single-step anodization for synthesis of hierarchical $\mathrm{TiO} 2$ nanotube arrays on foil and wire substrate for enhanced photoelectrochemical water 
splitting, International Journal of Hydrogen Energy, 38 (2013) 2062-2069

30. Y. Smith, R.S. Ray, K. Carlson, B. Sarma, M. Misra, Self-Ordered Titanium Dioxide Nanotube Arrays: Anodic Synthesis and Their Photo/Electro-Catalytic Applications, Materials, 6 (2013) 2892-2957

31. B. Sarma, Y. Smith, S. Mohanty, M. Misra, Electrochemical deposition of CdO on anodized $\mathrm{TiO} 2$ nanotube arrays for enhanced photoelectrochemical properties, Materials Letters, 85 (2012) $33-36$

32. R. S. Ray, B. Sarma, S. Mohanty, M. Misra, Theoretical and experimental study of sensing triacetone triperoxide (TATP) explosive through nanostructured TiO2 substrate, Talanta, 118 (2014) 304-311

33. Y. Xie, L. Zhou, C. Huang, H. Huang, J. Lu, Electrochim. Acta, Fabrication of nickel oxideembedded titania nanotube array for redox capacitance application, 53 (2008) 3643-3649

34. Donald N. Okoli, Cecilia N.Okoli, Optimal Growth and Characterization of Cobalt Sulphide Thin Films Fabricated Using the Chemical Bath Deposition Technique, Journal of Natural Sciences Research, 2 (2012) 5-8

35. M. - S. Wu, Electrochemical capacitance from manganese oxide nanowire structure synthesized by cyclic voltammetric electrodeposition, Applied Physics Letters, 87 (2005) 153102

36. B. J. Tan, K. J. Klabunde, P. M. A. Sherwood, XPS studies of solvated metal atom dispersed (SMAD) catalysts. Evidence for layered cobalt-manganese particles on alumina and silica, J. Am. Chem. Soc., 113 (1991) 855-861

37. N.S. Mclntyre, M.G. Cook, X-ray photoelectron studies on some oxides and hydroxides of cobalt, nickel, and copper, Anal. Chem., 47 (1975) 2208-2213

38. A. M. de Jong, V. H. J. de Beer, J. A. Rob van Veen, J. W. Niemantsverdriet, Surface Science Model of a Working Cobalt-Promoted Molybdenum Sulfide Hydrodesulfurization Catalyst: Characterization and Reactivity, J. Phys. Chem., 100 (1996) 17722.

39. S. M. Park, W. Li, J. Yu, H. Du, Sol-Gel Synthesis of Highly Dispersed Cobalt Nanoparticles on Silica Thin Films, J. Mater. Res., 20 (2005) 3094

40. K.S. Kim, X-ray-photoelectron spectroscopic studies of the electronic structure of CoO, Phys. Rev. B: Condens. Matter 11 (1975) 2177

41. C.-C. Hu, T.-Y. Hsu, Effects of complex agents on the anodic deposition and electrochemical characteristics of cobalt oxides, Electrochim. Acta. 53 (2008) 2386-2395

42. M.-J. Deng, F. LuHuang, I.-W. Sun, W.-T. Tsai, J.-K. Chang, An entirely electrochemical preparation of a nano-structured cobalt oxide electrode with superior redox activity, Nanotechnology. 20 (2009) 175602 
43. L. Hou, C. Yuan, D. Li, L. Yang, L. Shen, F. Zhang, X. Zhang, Electrochemically induced transformation of $\mathrm{NiS}$ nanoparticles into $\mathrm{Ni}(\mathrm{OH}) 2$ in $\mathrm{KOH}$ aqueous solution toward electrochemical capacitors, Electrochimica Acta 56 (2011) 7454- 7459

44. C. Yuan, B. Gao, L. Su, L. Chen, X. Zhang, Electrochemically Induced Phase Transformation and Charge-Storage Mechanism of Amorphous $\mathrm{CoS}_{\mathrm{x}}$ Nanoparticles Prepared by InterfaceHydrothermal Method Nanoparticles J. Electrochem. Soc., 156 (2009) A199-A203

45. B. Wang, J. Park, D. Su, C. Wang, H. Ahn, G. Wang, Solvothermal synthesis of CoS2-graphene nanocomposite material for high-performance supercapacitors, J Mater. Chem., 22 (2012) $15750-15756$

46. Q.H. Huang, X.Y. Wang and J. Li, Characterization and performance of hydrous manganese oxide prepared by electrochemical method and its application for supercapacitors, Electrochim. Acta, 52 (2007) 1758.

47. N.L. Wu, S.Y. Wang, C.Y. Han, D.S. Wu, L.R. Shiue, Electrochemical capacitor of magnetite in aqueous electrolytes, J. Power Sources, 113 (2003) 173-178 
Figure 1: The top view of the T-NT arrays formed after anodization at 40V for $1 \mathrm{hr}$., the inset shows the cross-sectional view.

Figure 2: Cyclic voltammetry of the T-NT substrate in aqueous solution of $10 \mathrm{mM}$ cobalt chloride $\left(\mathrm{CoCl}_{2} \cdot 6 \mathrm{H} 2 \mathrm{O}\right)$ and $0.5 \mathrm{M}$ thiourea $\left(\left(\mathrm{NH}_{2}\right)_{2} \mathrm{CS}\right)$ at a scan rate of $20 \mathrm{mV} \mathrm{s}^{-1}$.

Figure 3: Morphology of the CoS deposit on T-NT obtained after potentiostatic deposition at (a) $-0.5 \mathrm{~V}$, (b) $-1.5 \mathrm{~V}$, and (c) CV deposition (10 cycles between $-0.5 \mathrm{~V}$ and $-1.5 \mathrm{~V})$. The underneath T-NT substrate showing CoS nanoparticles decorating the rim of the tubes after deposition (d) CV $(10$ cycles between $-0.5 \mathrm{~V}$ and $-1.5 \mathrm{~V}),(\mathrm{e})-1.5 \mathrm{~V}$

Figure 4: XRD profile for the T-NT/CoS electrode prepared by CV deposition.

Figure 5: (a) Co 2p XPS spectra of the T-NT/CoS electrode, (b) S 2p XPS spectra obtained in the T-NT/CoS electrode

Figure 6: (a) CV profiles of the T-NT/CoS electrode in 2M KOH electrolyte at various scan rates (inset shows the profile at $1 \mathrm{mV} \mathrm{s}^{-1}$ ) (b) Variations in the specific capacitance of the T-NT/CoS electrode as the function of scan rate. (c) The $1^{\text {st }}$ and $300^{\text {th }} \mathrm{CV}$ profiles recorded at a scan rate of $300 \mathrm{mV} \mathrm{s}^{-1}$ for the composite electrode. Excellent stability of the capacitance behavior can be observed from the CV profiles.

Figure 7: Morphology of the T-NT/CoS electrode after 300 numbers of repetitive CV cycles in 2M KOH electrolyte. The $\mathrm{CoS}$ deposit changed to a plate-like morphology with approximate plate thickness of $80 \mathrm{~nm}$ (inset figure). 
Figure 8: CV profiles of the T-NT/CoS electrode in (a) $1 \mathrm{M} \mathrm{Na}_{2} \mathrm{SO}_{4}$, (b) $1 \mathrm{M} \mathrm{Na}_{2} \mathrm{SO}_{3}$, and (c) $2 \mathrm{M}$ $\mathrm{KCl}$ electrolytes at various scan rates (insets show the profile at $1 \mathrm{mV} \mathrm{s}^{-1}$ ). (d) Comparison of $\mathrm{CV}$ profiles in these electrolytes at $20 \mathrm{mV} \mathrm{s}^{-1}$.

Figure 9: (a) Anodic current peaks from the CV profiles in Figure 8(a-c) obtained for the TNT/CoS electrode in $1 \mathrm{M} \mathrm{Na}_{2} \mathrm{SO}_{4}, 1 \mathrm{M} \mathrm{Na}_{2} \mathrm{SO}_{3}$, and $2 \mathrm{M} \mathrm{KCl}$ electrolytes as the function of scan rate. (b) Variations in the specific capacitance of the T-NT/CoS electrode in $1 \mathrm{M} \mathrm{Na} \mathrm{SO}_{4}, 1 \mathrm{M}$ $\mathrm{Na}_{2} \mathrm{SO}_{3}$, and $2 \mathrm{M} \mathrm{KCl}$ electrolytes as the function of scan rate.

Figure 10: Comparisons of CV profiles $\left(1^{\text {st }}, 100^{\text {th }}\right.$, and $300^{\text {th }}$ cycles $)$ of the T-NT/CoS electrode in (a) $1 \mathrm{M} \mathrm{Na}_{2} \mathrm{SO}_{4}$, (b) $1 \mathrm{M} \mathrm{Na}_{2} \mathrm{SO}_{3}$, and (c) $2 \mathrm{M} \mathrm{KCl}$ electrolytes at a scan rate of $100 \mathrm{mV} \mathrm{s}^{-1}$

Figure 11: Morphology of the T-NT/CoS electrode after 300 cycles of repetitive CV cycles in (a) $1 \mathrm{M} \mathrm{Na}_{2} \mathrm{SO}_{4}$, (b) $1 \mathrm{M} \mathrm{Na}_{2} \mathrm{SO}_{3}$, and (c) $2 \mathrm{M} \mathrm{KCl}$ electrolytes at a scan rate of $100 \mathrm{mV} \mathrm{s}^{-1}$.

Figure 12: Galvanostatic charge-discharge (V-t) profiles obtained at a current densities of 1, 3, and $5 \mathrm{~mA} \mathrm{~cm}{ }^{-2}$ for the T-NT/CoS electrode in (a) $1 \mathrm{M} \mathrm{Na}_{2} \mathrm{SO}_{4}$, (b) $1 \mathrm{M} \mathrm{Na}_{2} \mathrm{SO}_{3}$, and (c) $2 \mathrm{M} \mathrm{KCl}$ electrolytes. (d) Variations in the specific capacitance of the T-NT/CoS electrode in $1 \mathrm{M} \mathrm{Na}_{2} \mathrm{SO}_{4}$, $1 \mathrm{M} \mathrm{Na}_{2} \mathrm{SO}_{3}$, and $2 \mathrm{M} \mathrm{KCl}$ electrolytes as the function of charge-discharge current density.

Figure 13: (a) The variations in the specific capacitance of the T-NT/CoS electrode obtained at a charge discharge current density of $5 \mathrm{~mA} \mathrm{~cm}{ }^{-2}$ in $1 \mathrm{M} \mathrm{Na} \mathrm{SO}_{4}, 1 \mathrm{M} \mathrm{Na} \mathrm{SO}_{3}$, and $2 \mathrm{M} \mathrm{KCl}$ electrolytes. Inset is the representative charge-discharge (V-t) profiles recorded at the current density of $5 \mathrm{~mA} \mathrm{~cm}^{-2}$ for the composite electrode in these electrolytes. The V-t profiles obtained towards the end of the charge discharge cycles in (b) $1 \mathrm{M} \mathrm{Na}_{2} \mathrm{SO}_{4}$, (c) $1 \mathrm{M} \mathrm{Na} \mathrm{SO}_{3}$, and (d) $2 \mathrm{M}$ $\mathrm{KCl}$. 
Figure 14: Nyquist plot of the T-NT/CoS electrode in (a) $\mathrm{KOH}$ (inset shows the semi-circle domain at high frequency), (b) $\mathrm{Na}_{2} \mathrm{SO}_{4}, \mathrm{Na}_{2} \mathrm{SO}_{3}$, and $\mathrm{KCl}$ electrolytes.

Figure S1: (a) Co 2p XPS spectrum, (b) S 2p XPS spectrum of the T-NT/CoS electrode after repetitive $\mathrm{CV}$ cycles in $2 \mathrm{M} \mathrm{KOH}$ electrolyte

Figure S2: Comparative CV profiles of the T-NT, Ti/CoS, and T-NT/CoS electrodes in (a) $1 \mathrm{M}$ $\mathrm{Na}_{2} \mathrm{SO}_{4}$, (b) $1 \mathrm{M} \mathrm{Na}_{2} \mathrm{SO}_{3}$, (c) $2 \mathrm{M} \mathrm{KCl}$ and (d) $2 \mathrm{M} \mathrm{KOH}$ electrolytes recorded at $100 \mathrm{mV} \mathrm{s}^{-1}$.

Figure S3: (a) Co 2p XPS spectra, (b) S 2p XPS spectra of the T-NT/CoS electrode after repetitive $\mathrm{CV}$ cycles in $2 \mathrm{M} \mathrm{KCl}, 1 \mathrm{M} \mathrm{Na} 2 \mathrm{SO}_{3}$, and $1 \mathrm{M} \mathrm{Na}_{2} \mathrm{SO}_{4}$ electrolytes 
Figure 1

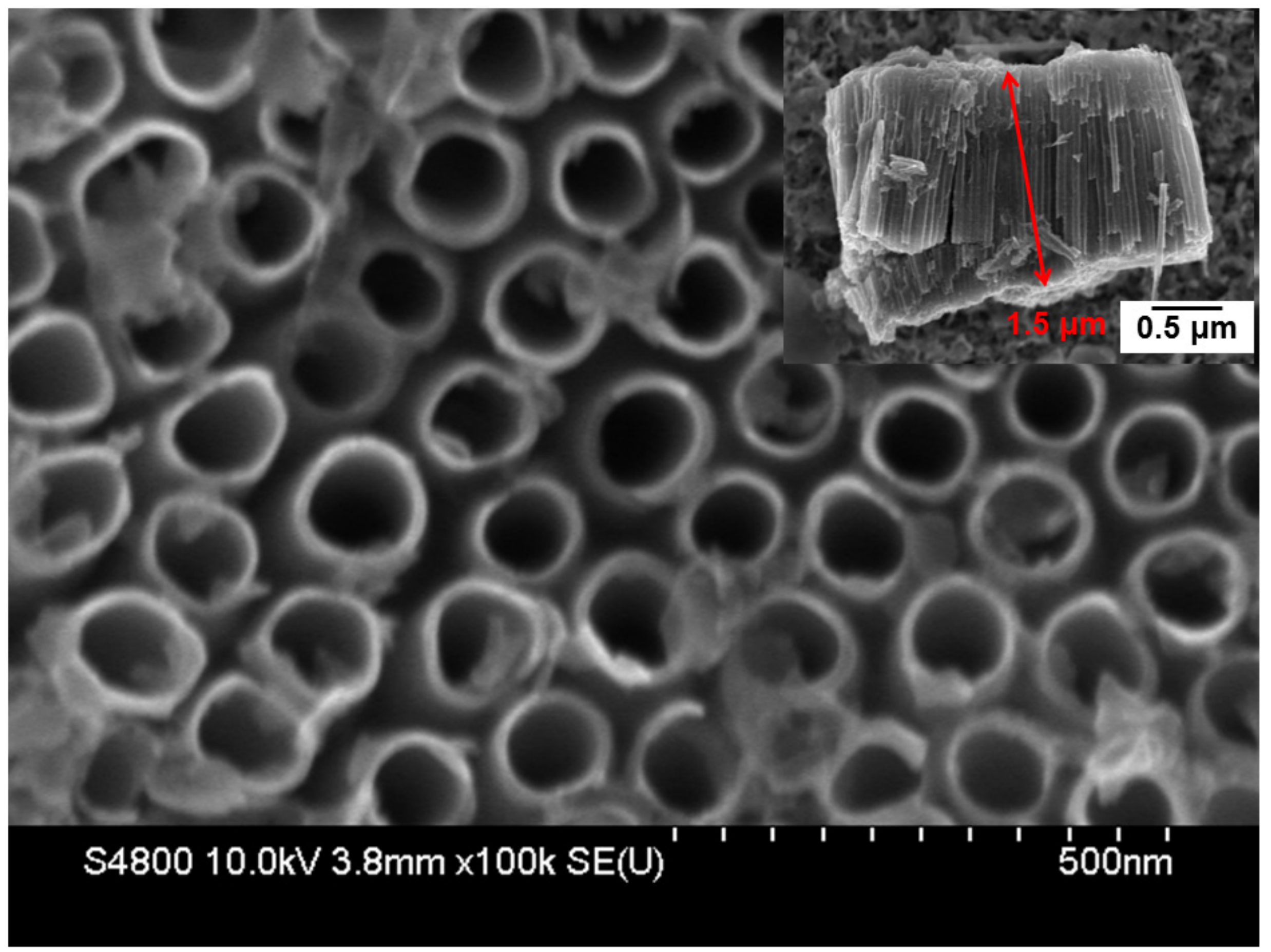


Figure 2

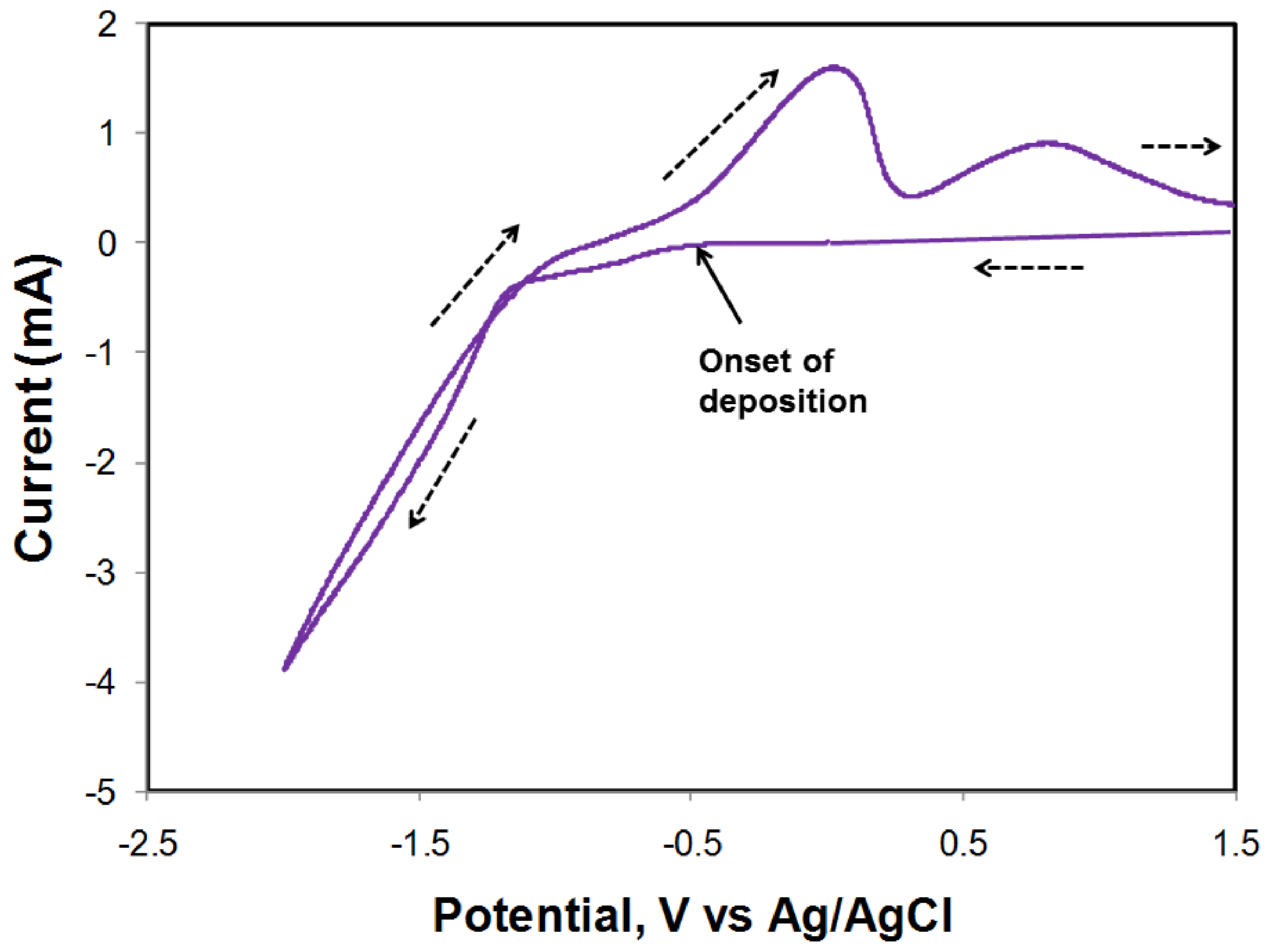


Figure 3a

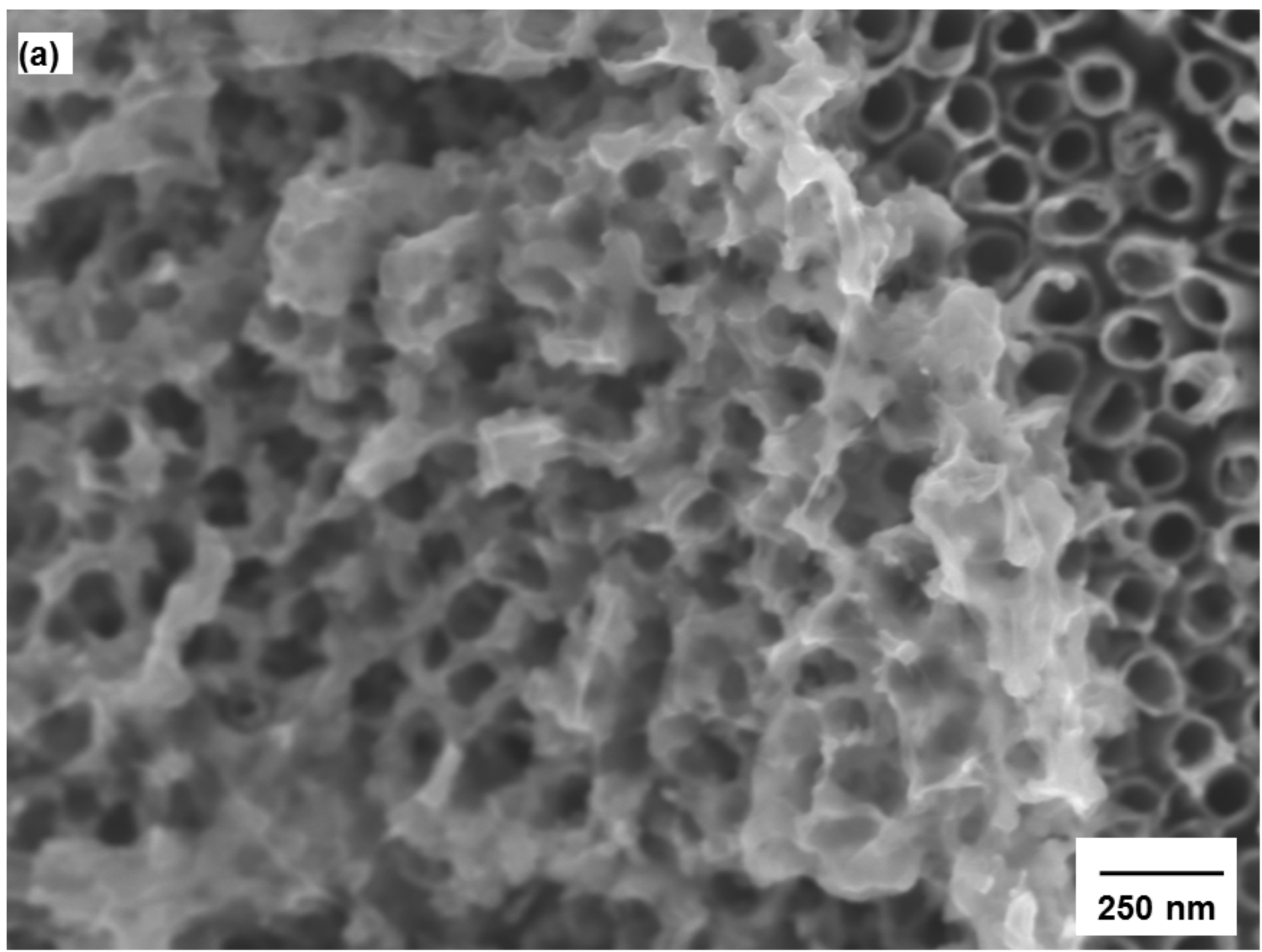


Figure $3 b$

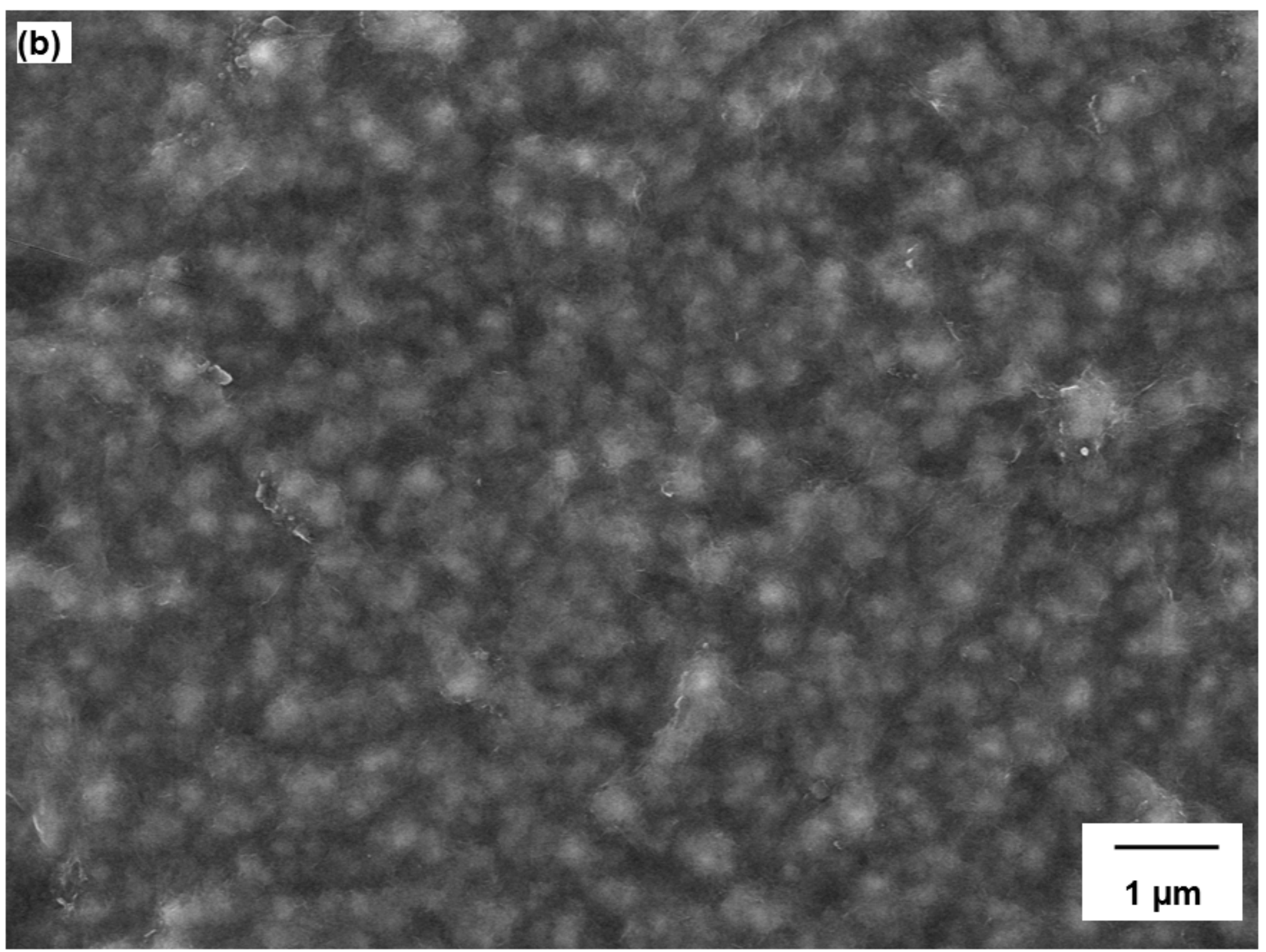


Figure 3c

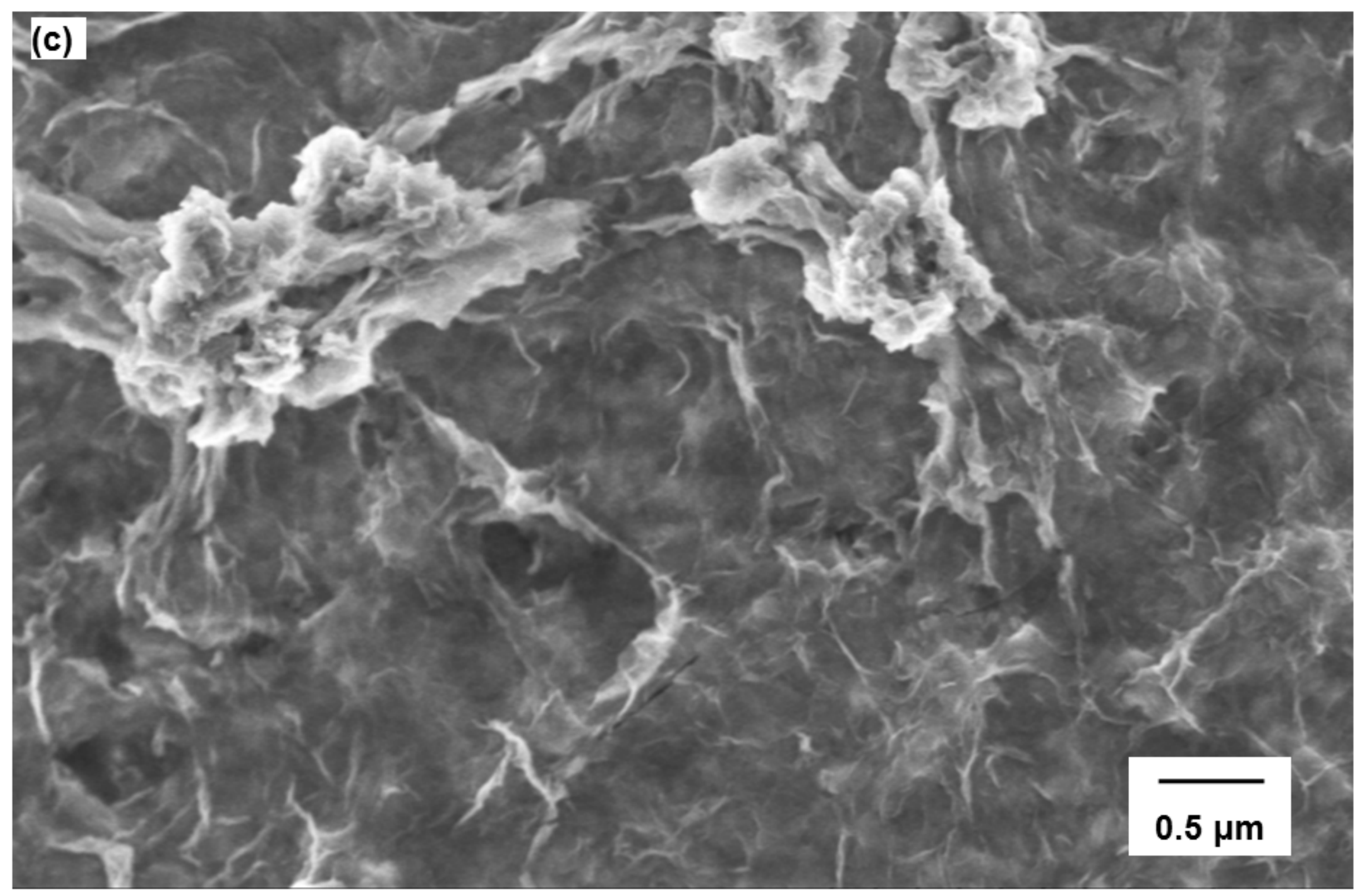


Figure 3d

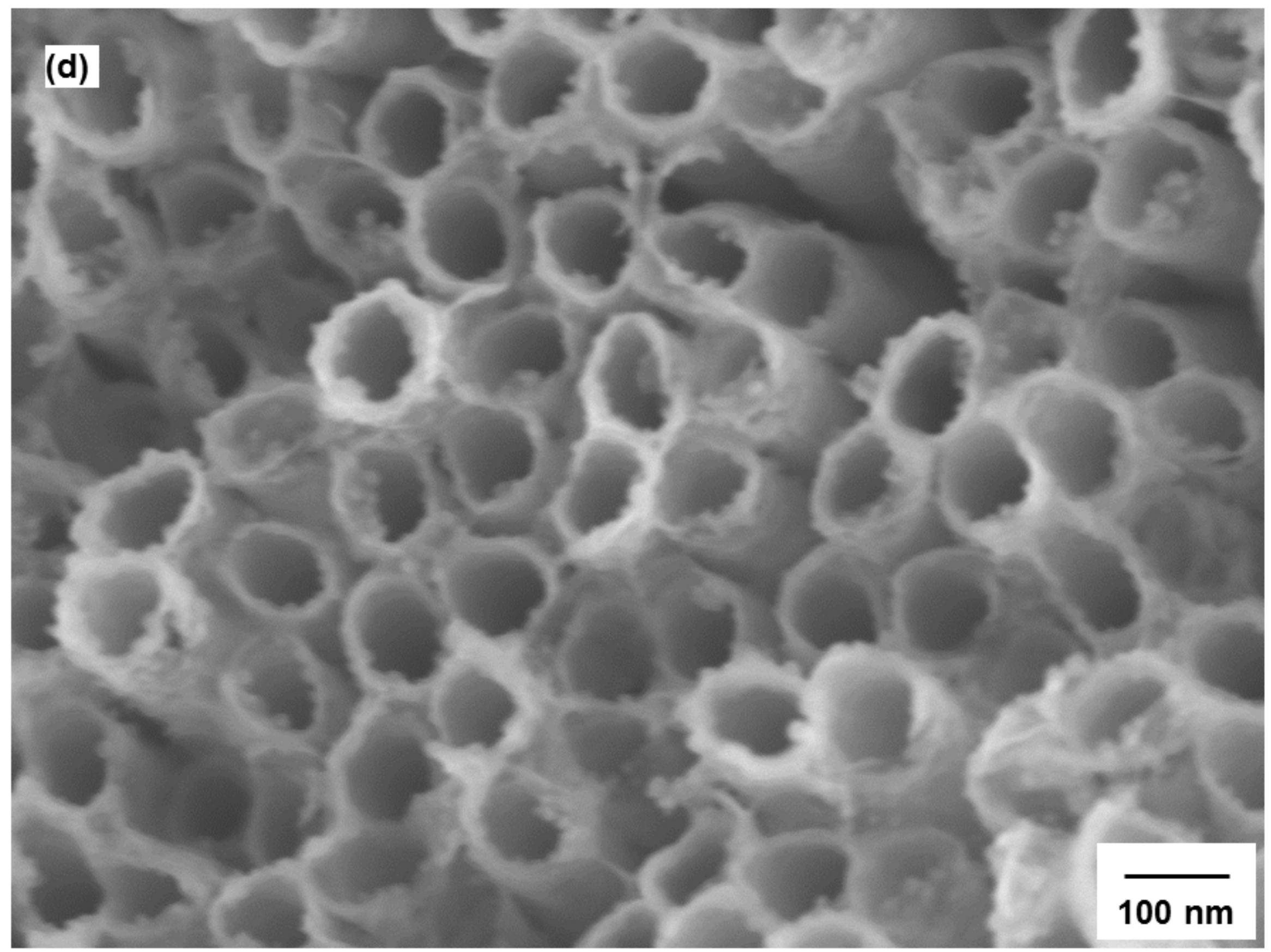


Figure $3 e$

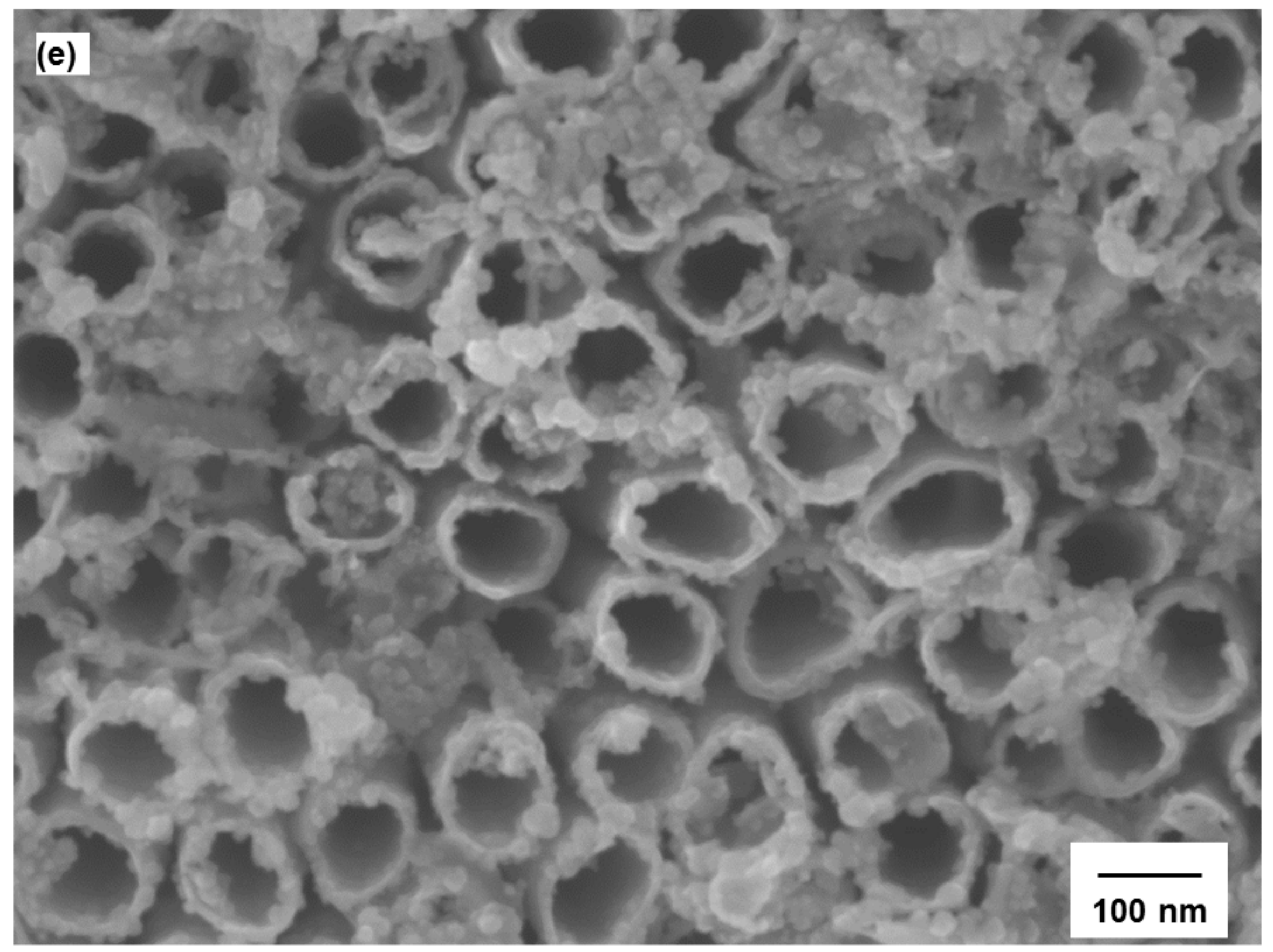


Figure 4

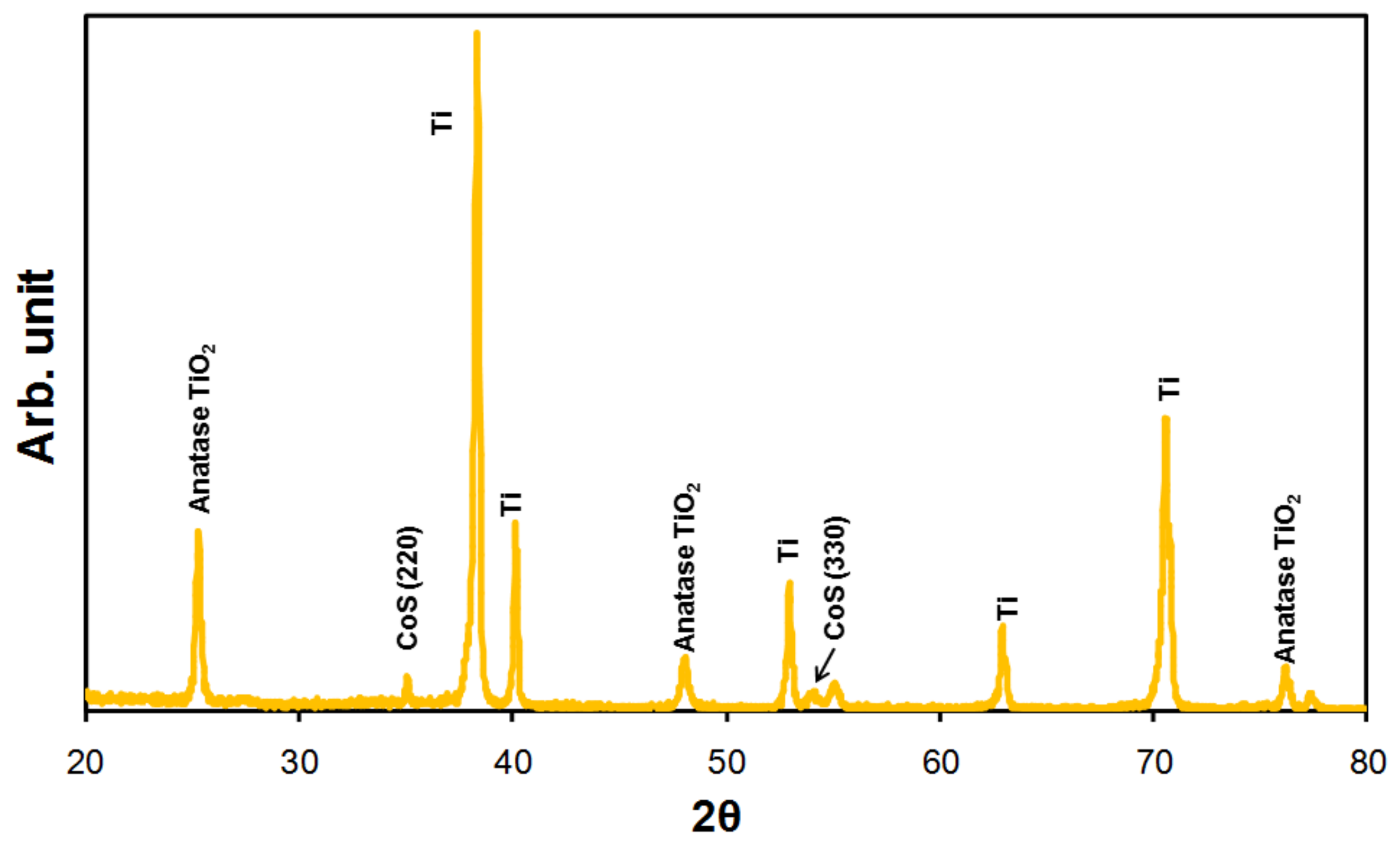


Figure 5a

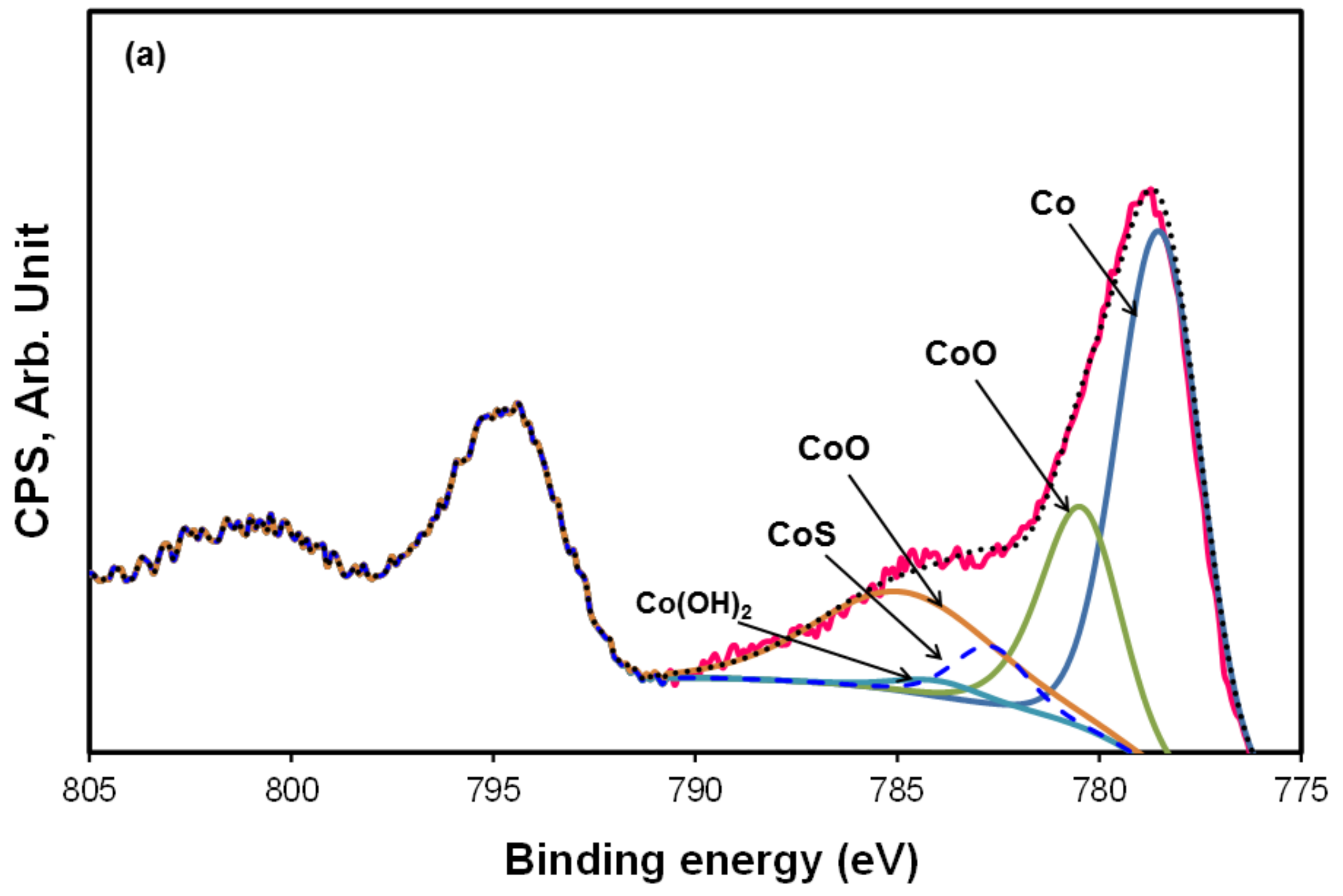


Figure 5b

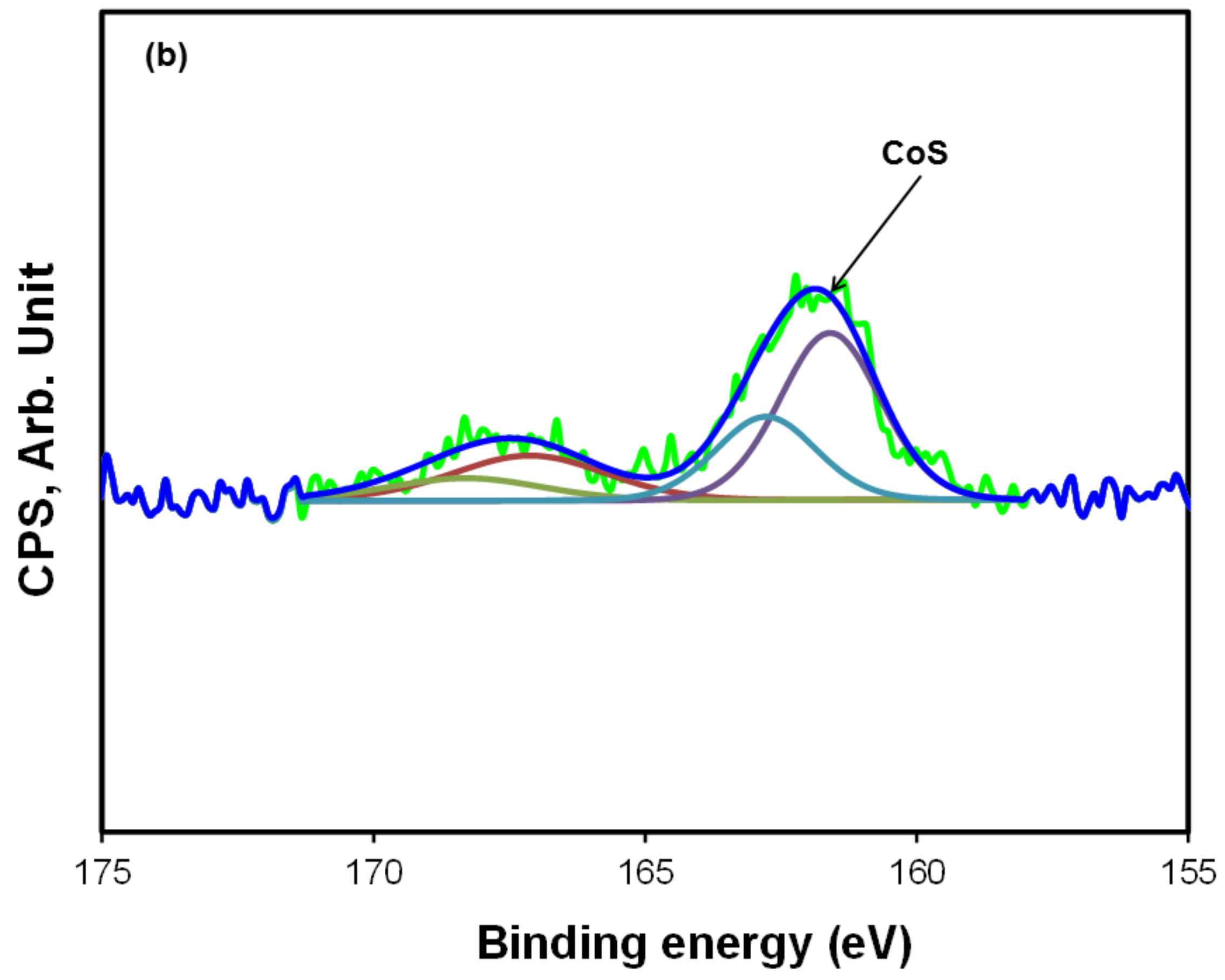


Figure $6 a$

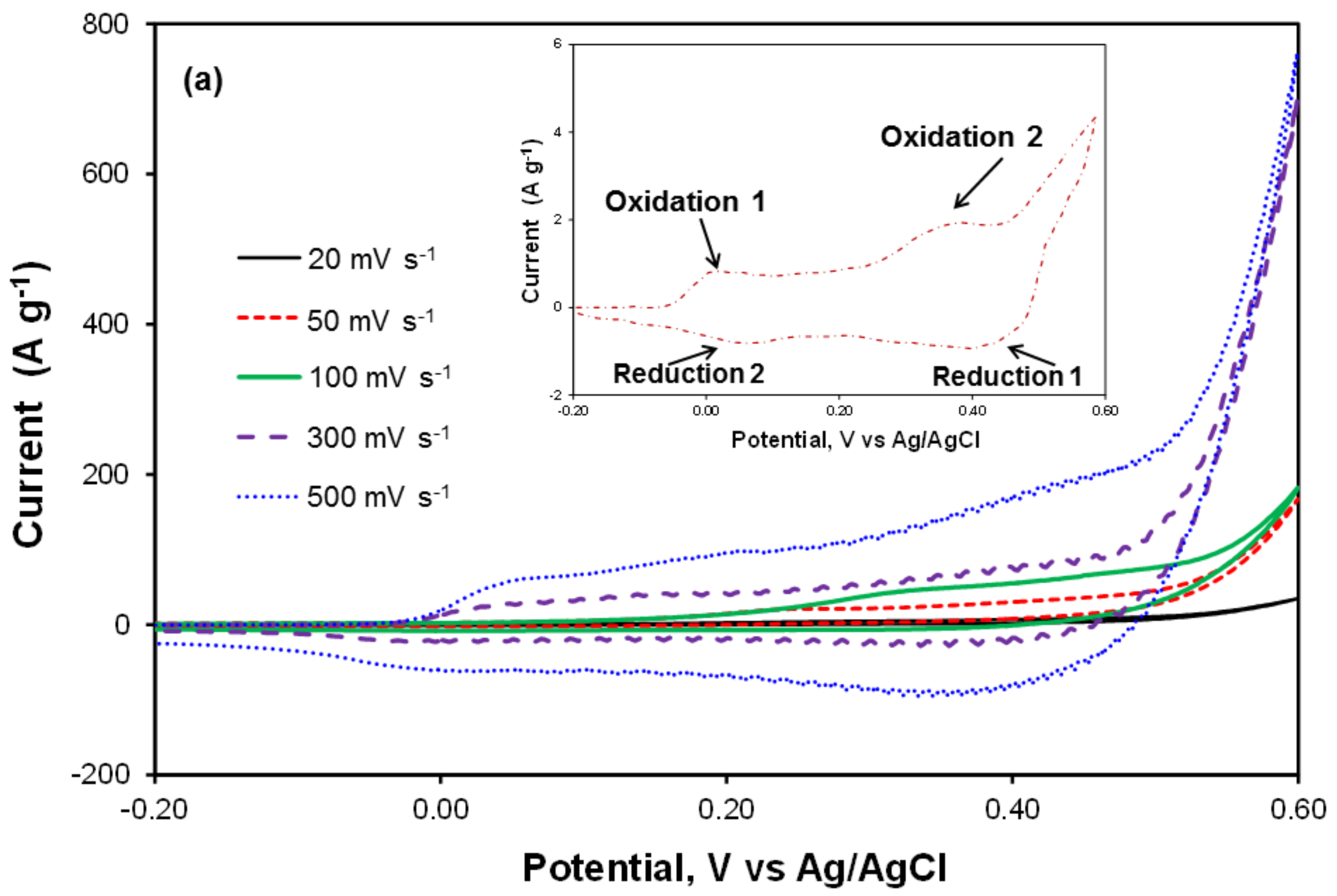


Figure $6 b$

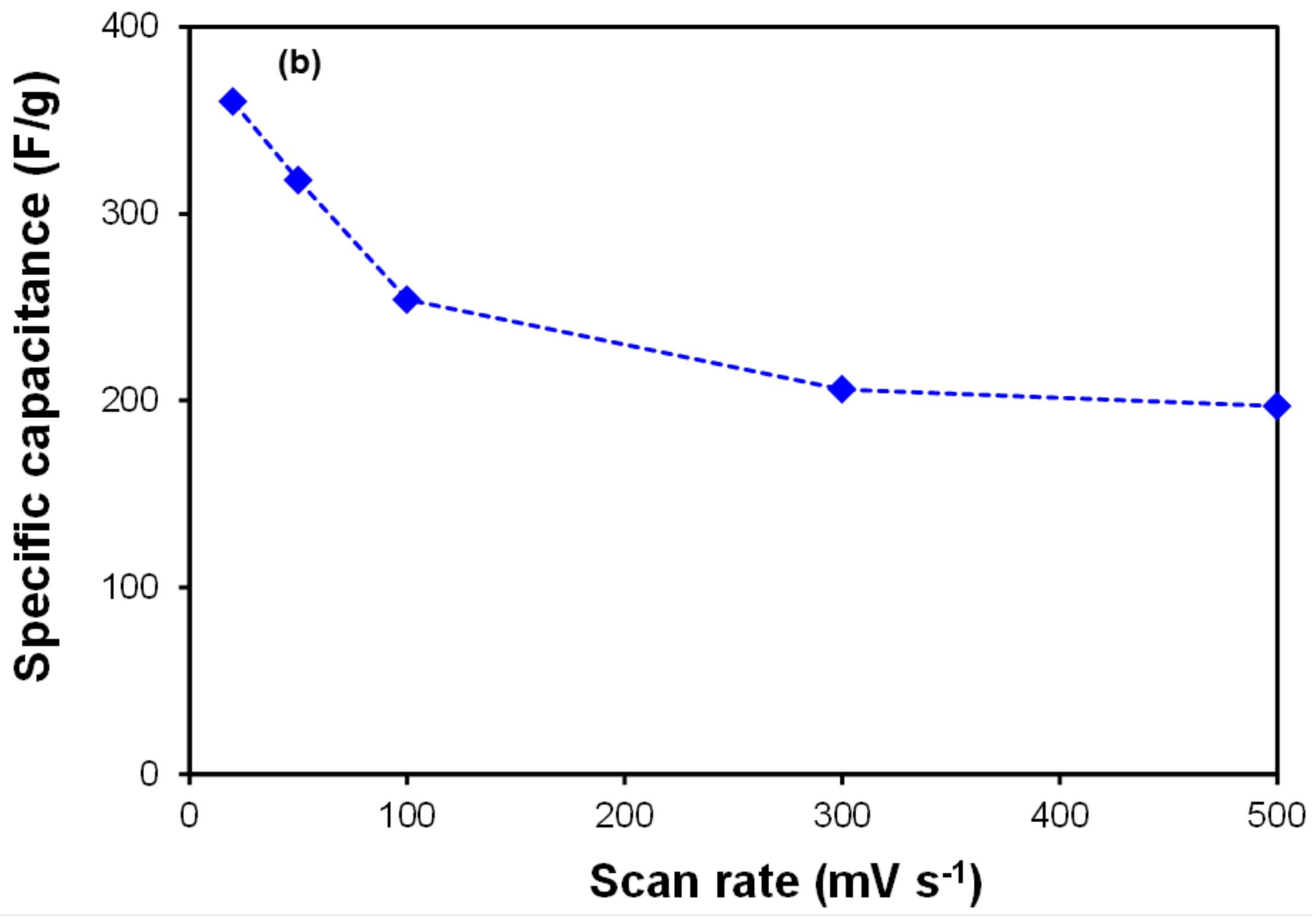


Figure $6 c$

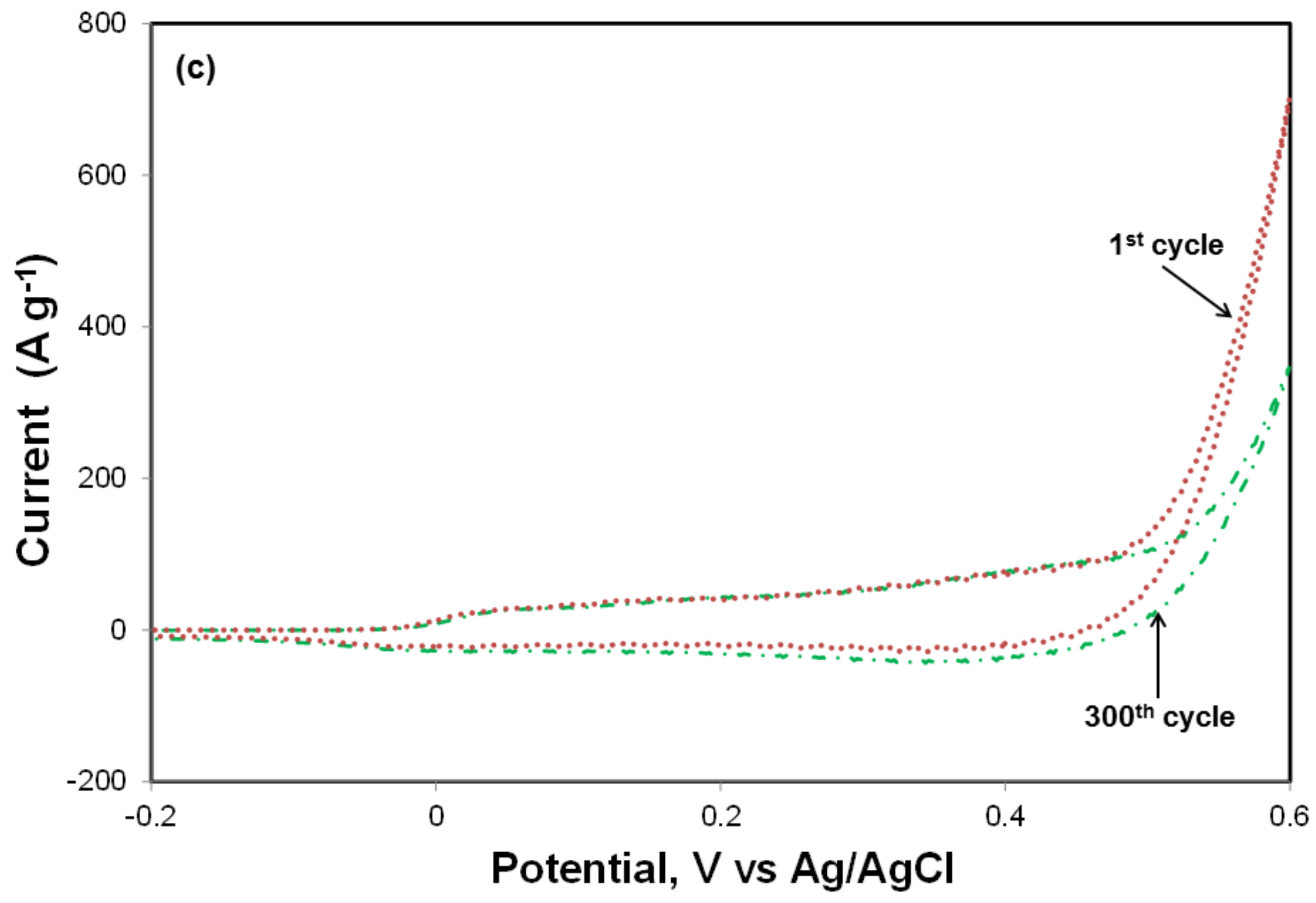


Figure 7

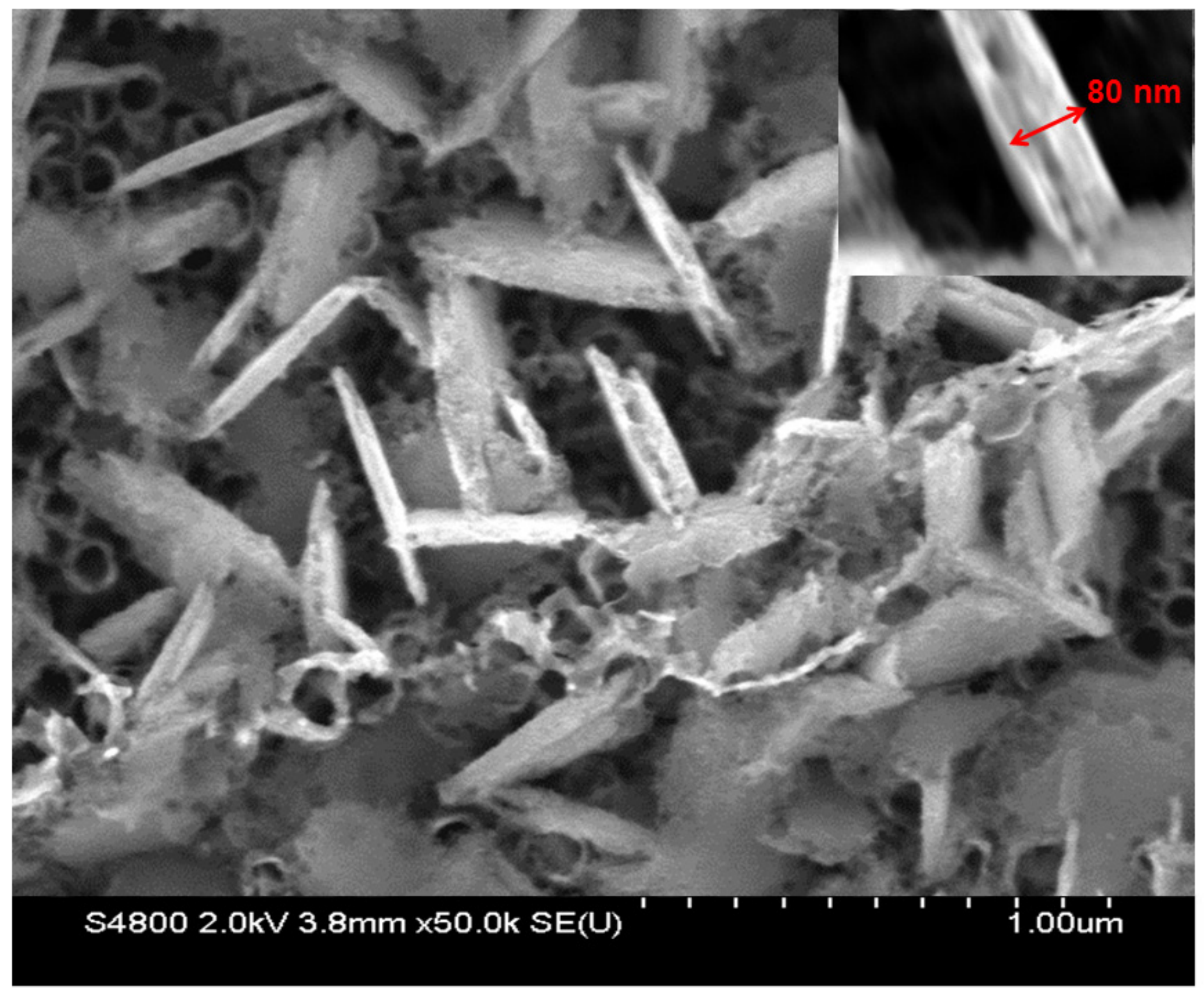


Figure $8 a$

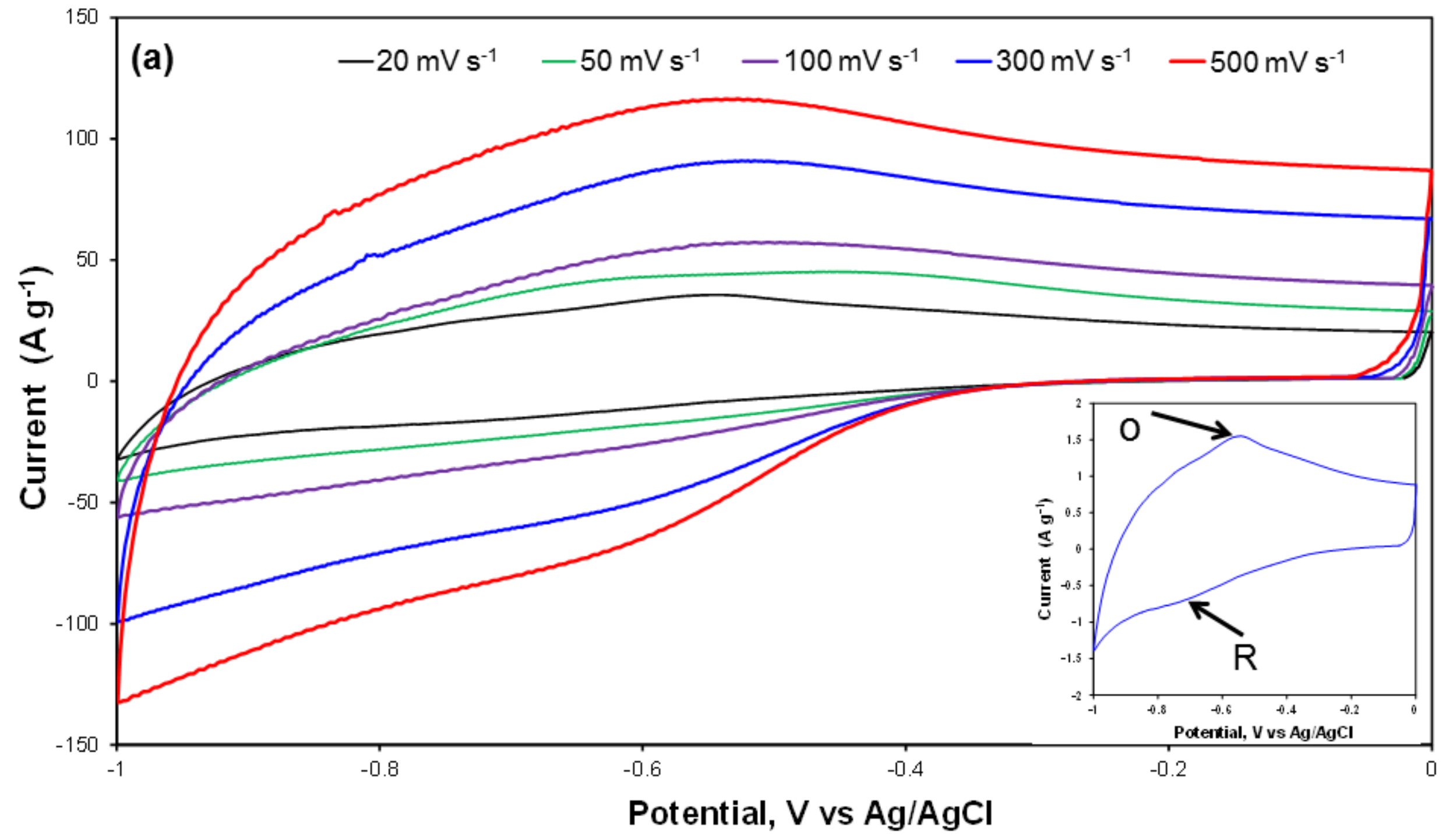


Figure 8b

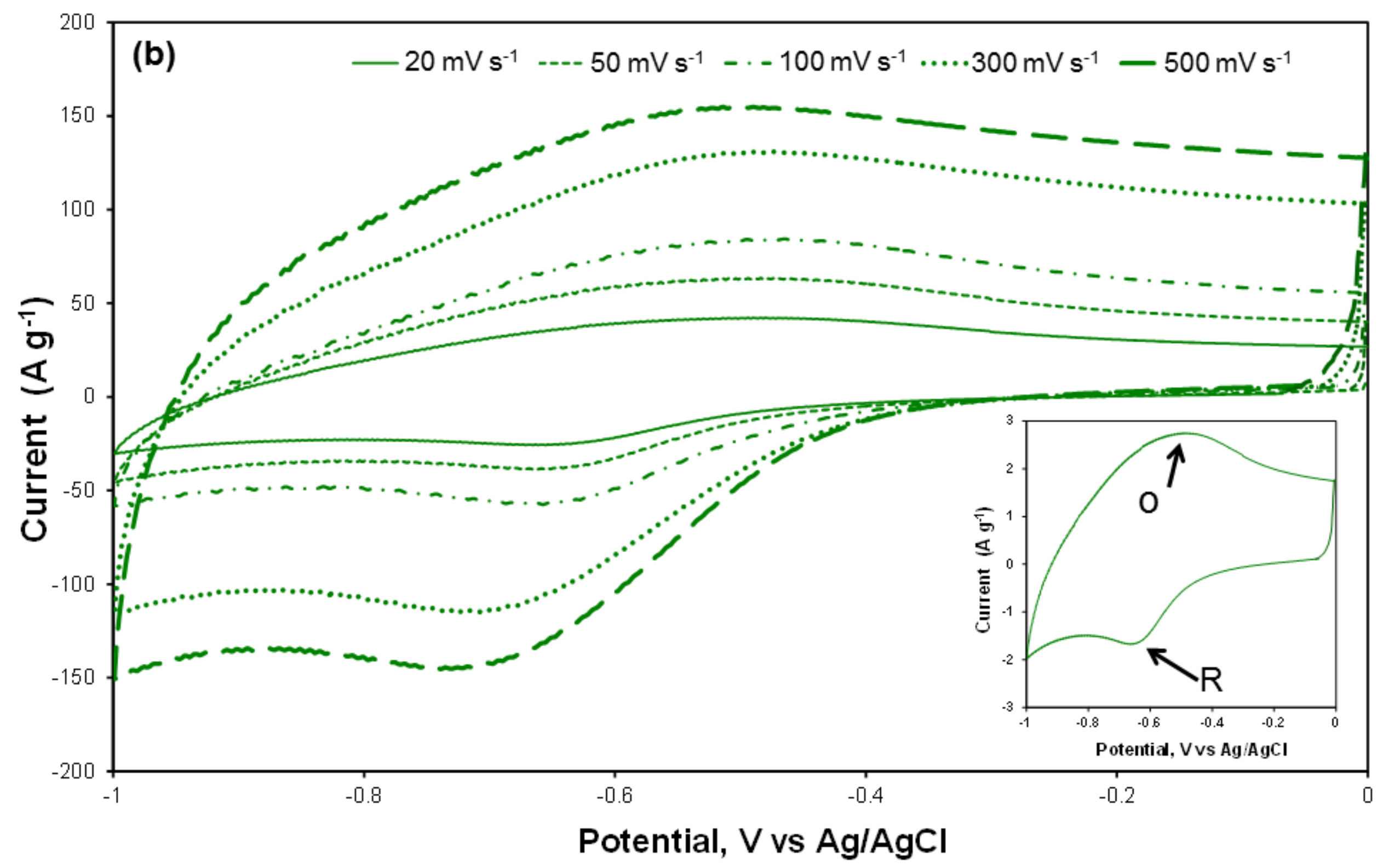


Figure 8c

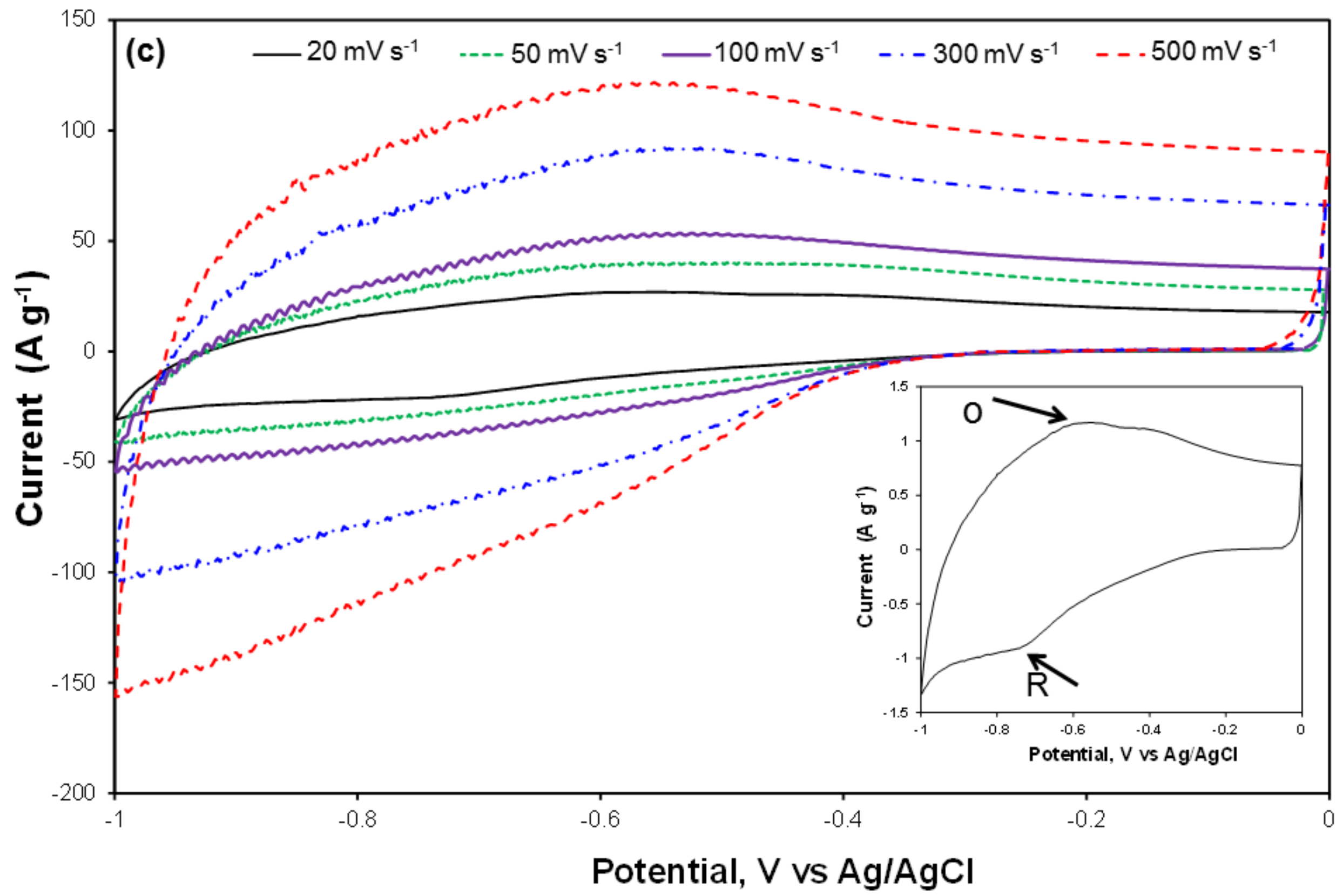


Figure 8d

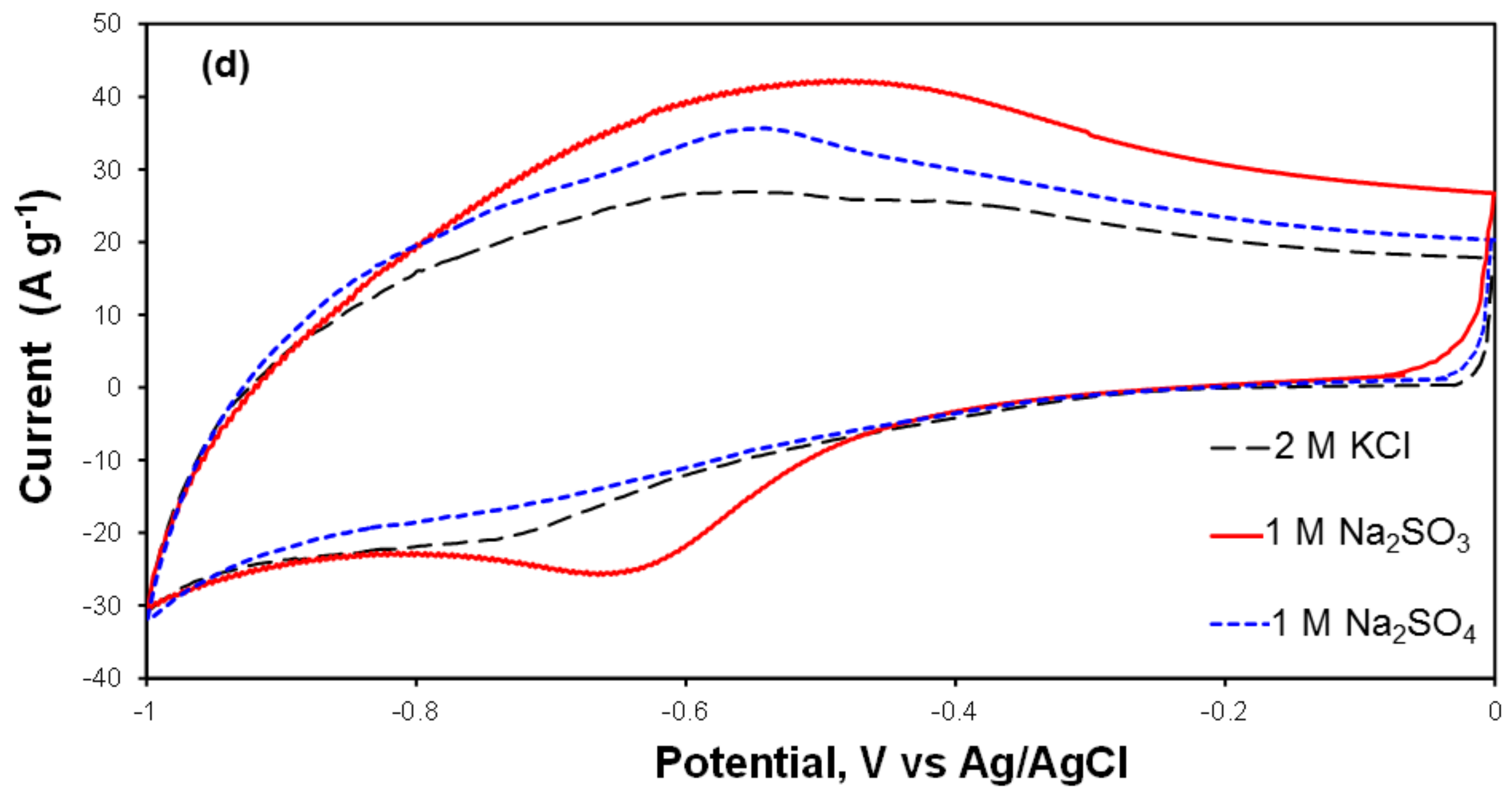


Figure 9a

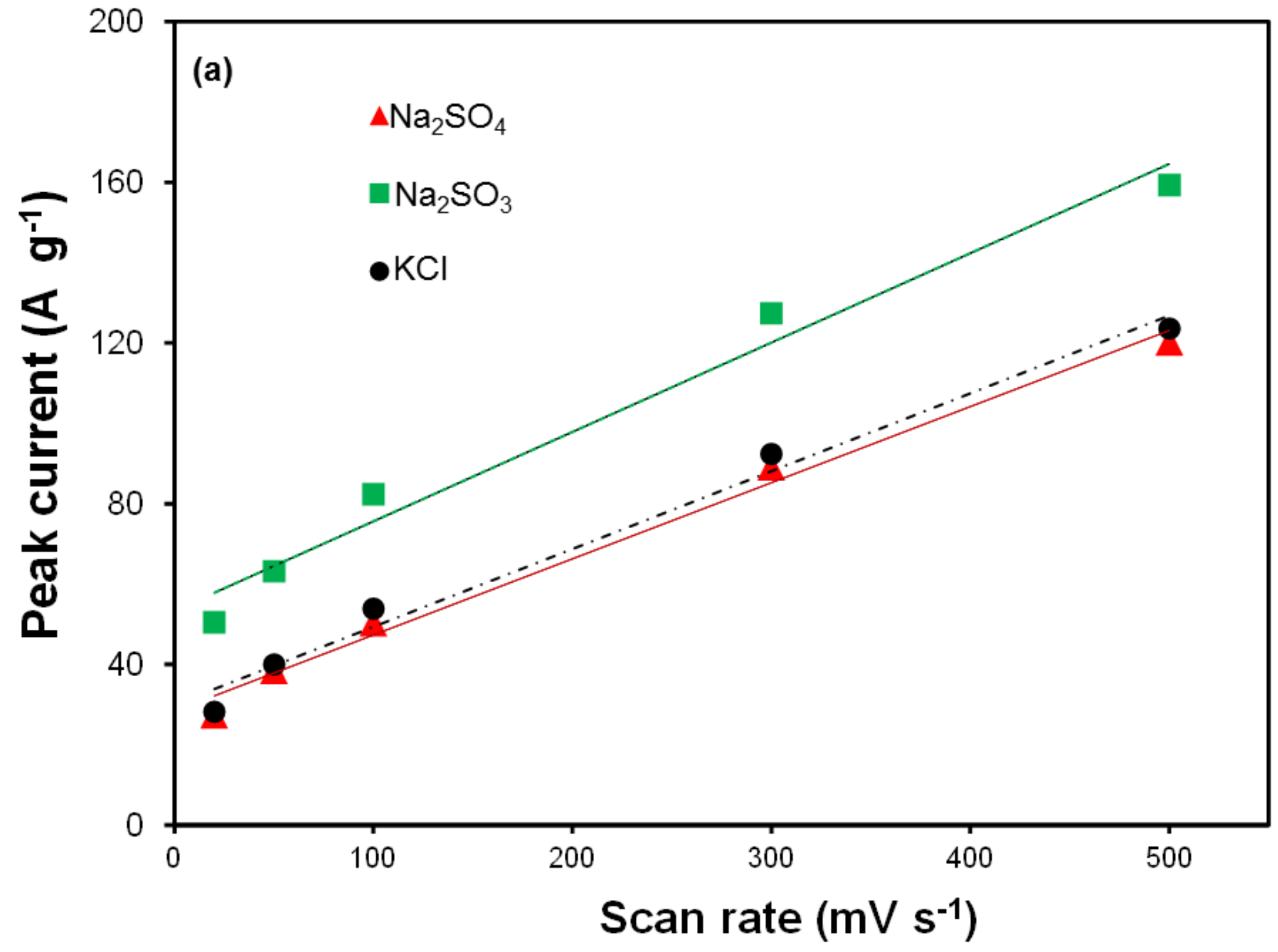


Figure 9b

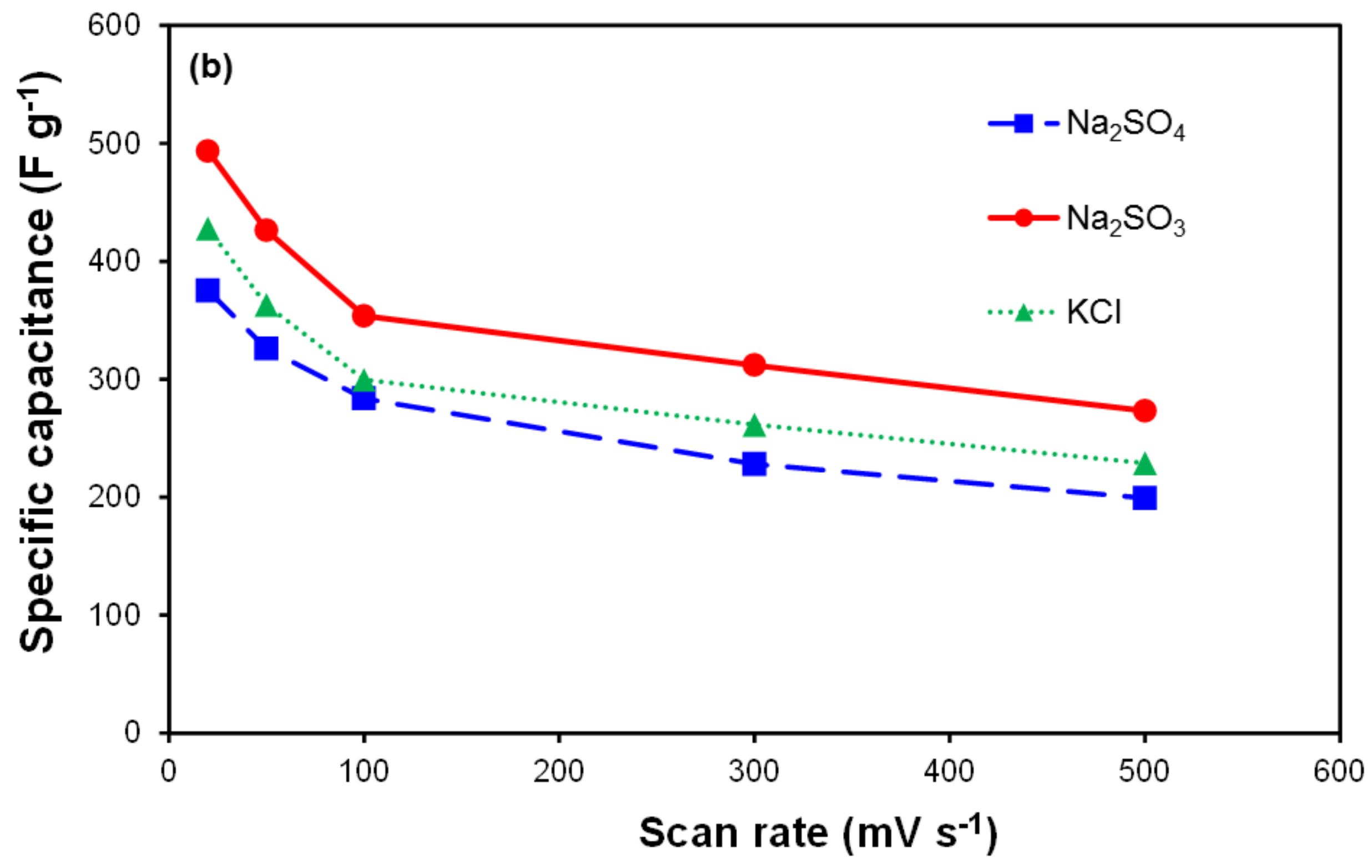




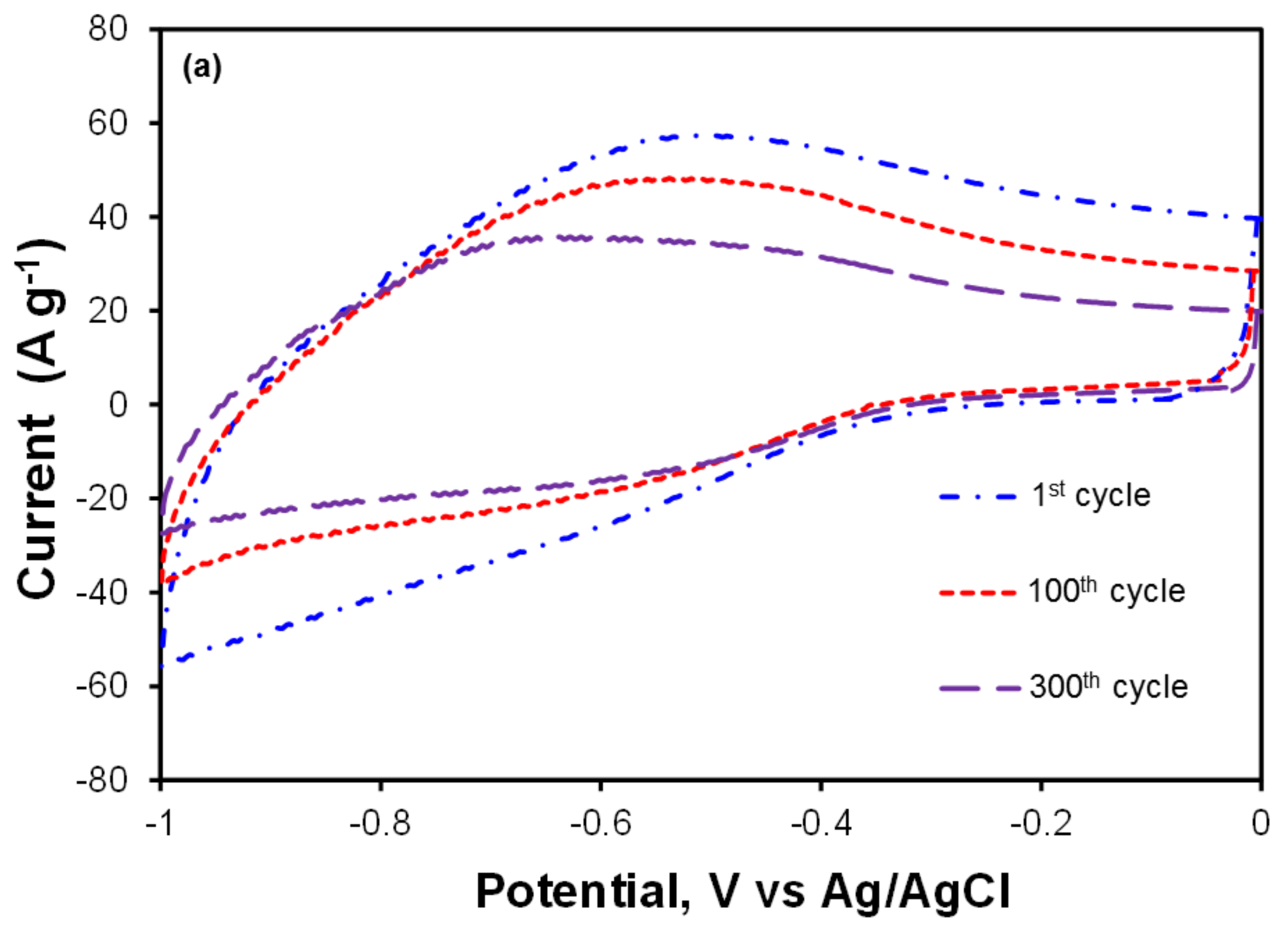


Figure 10b

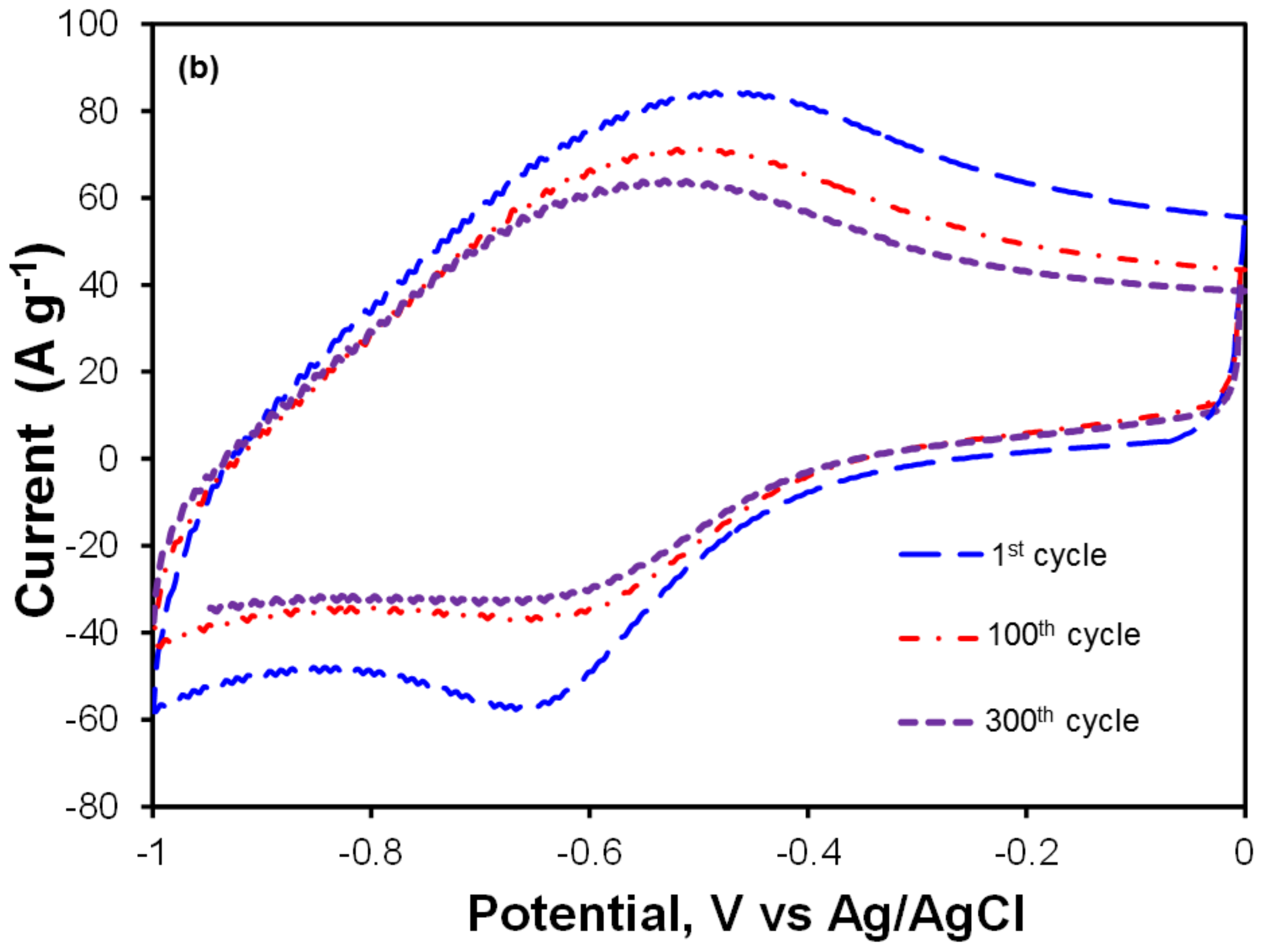


Figure 10c

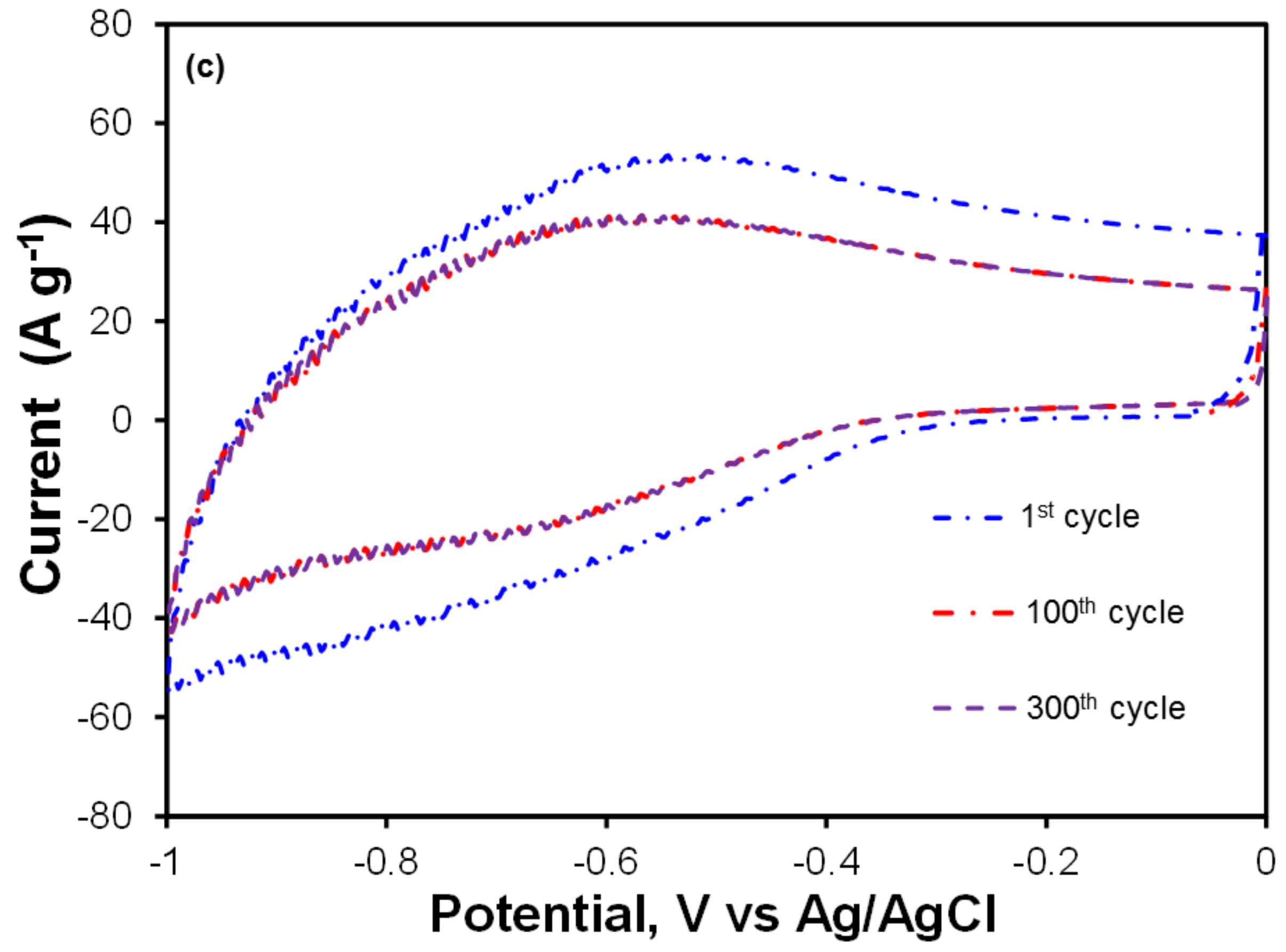


Figure 11a

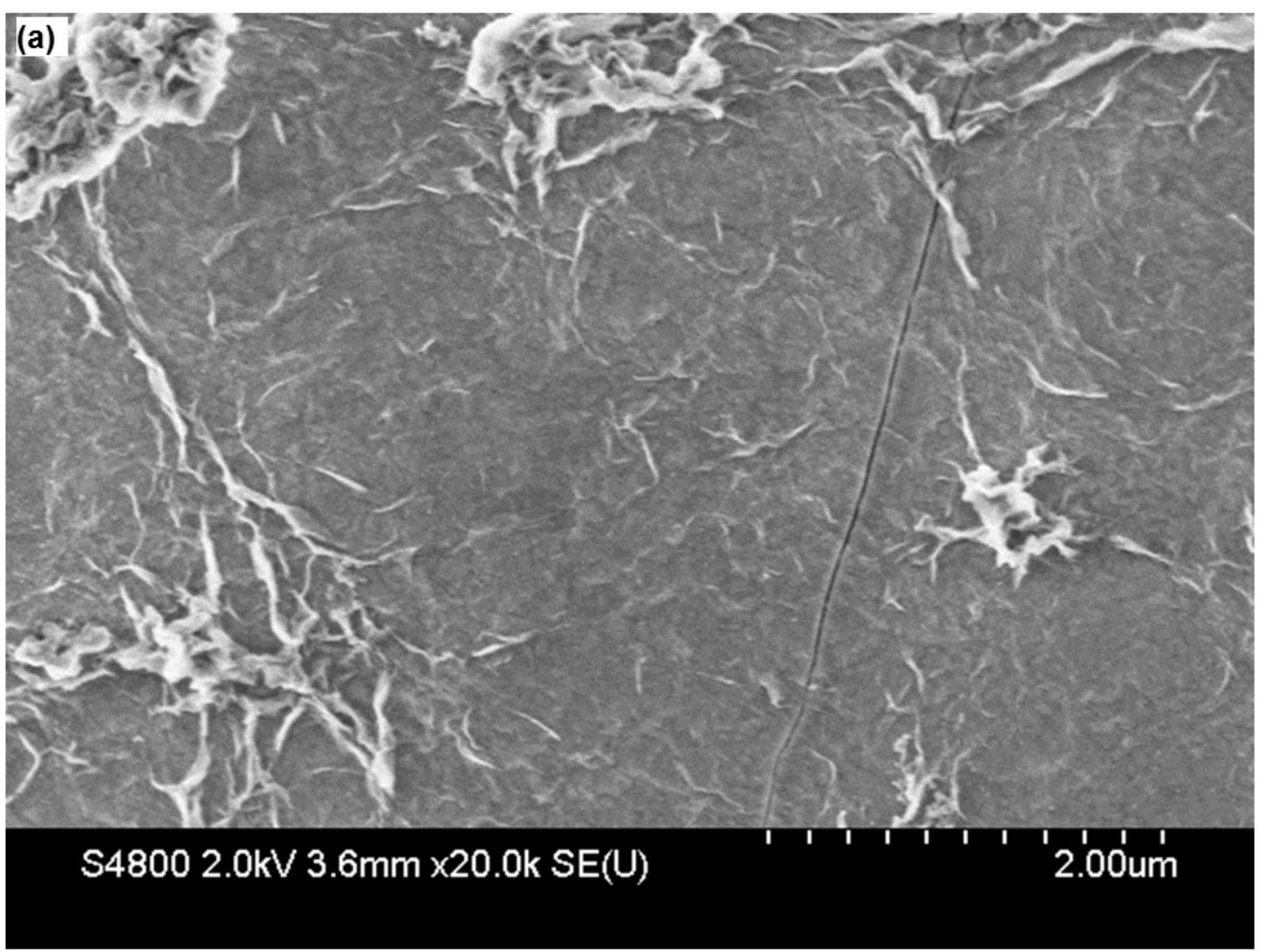




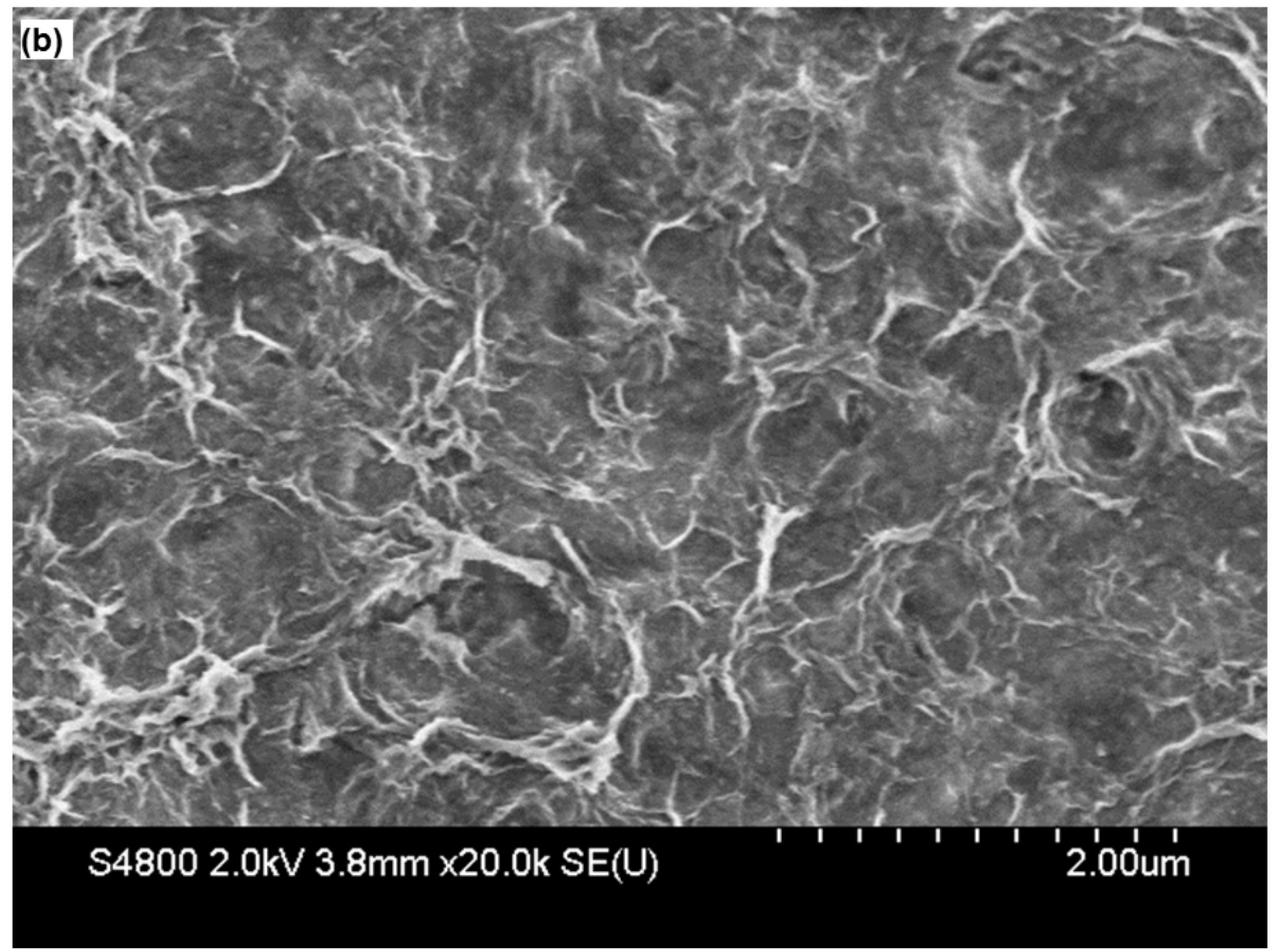


Figure 11c

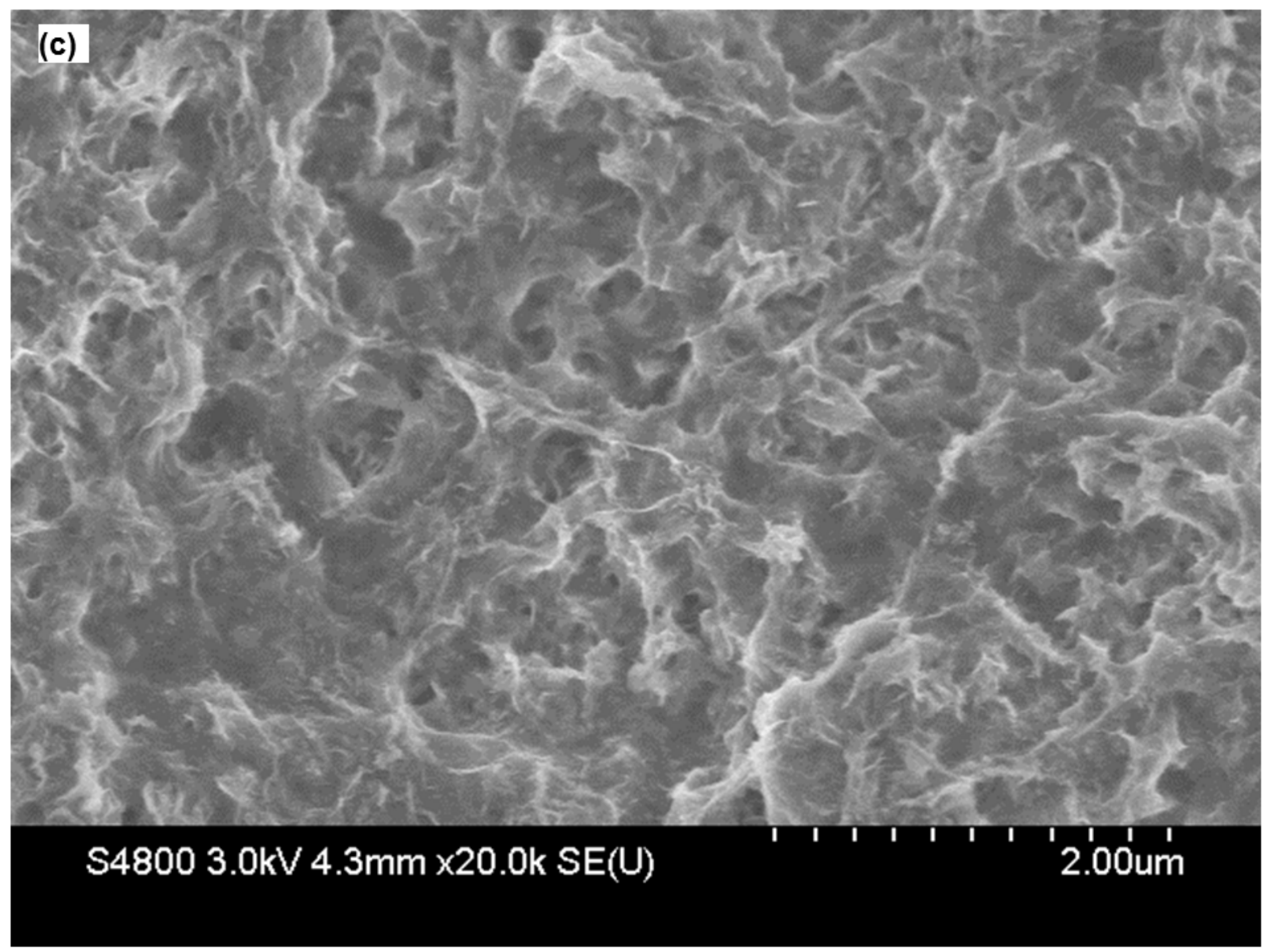




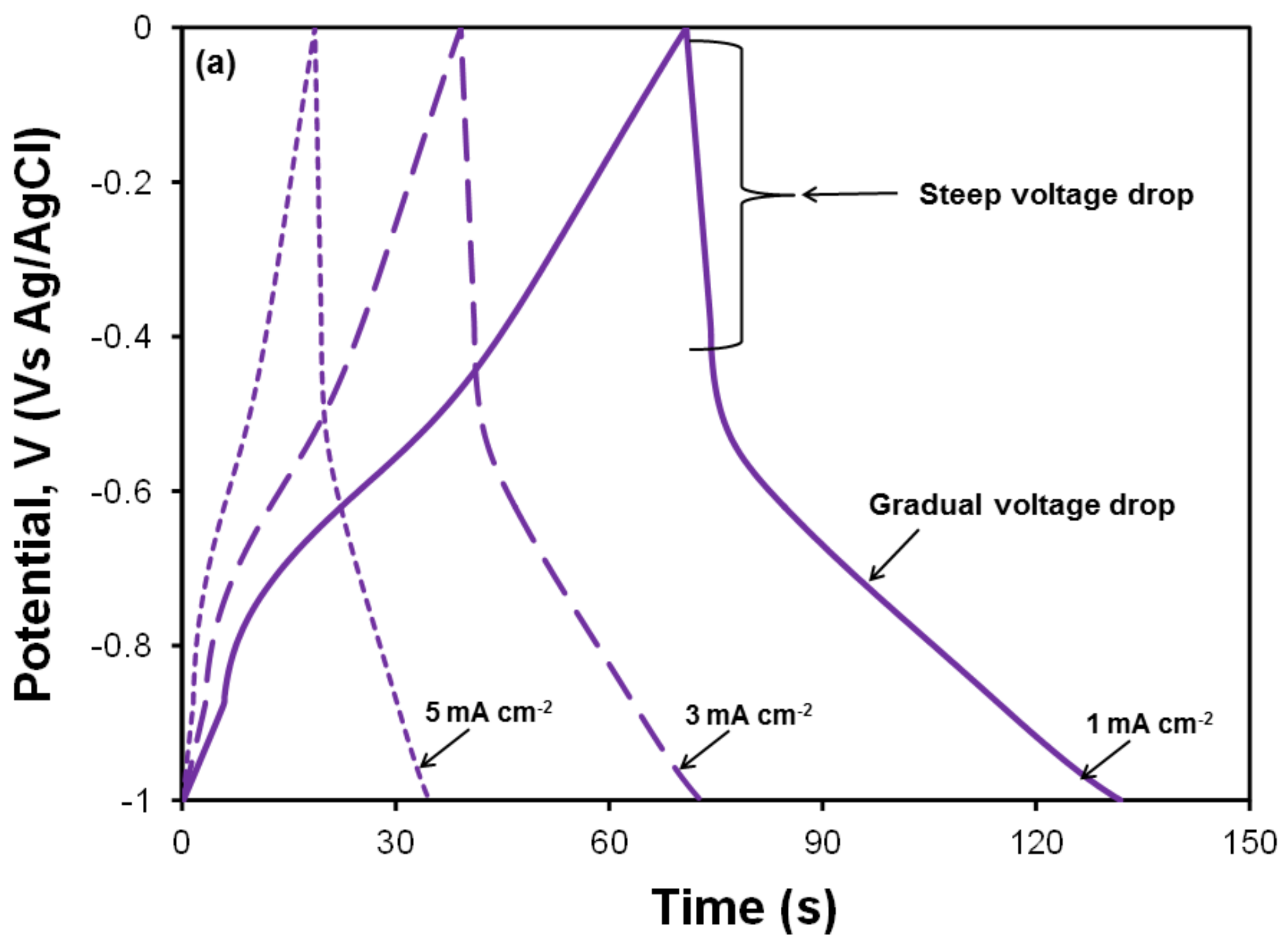




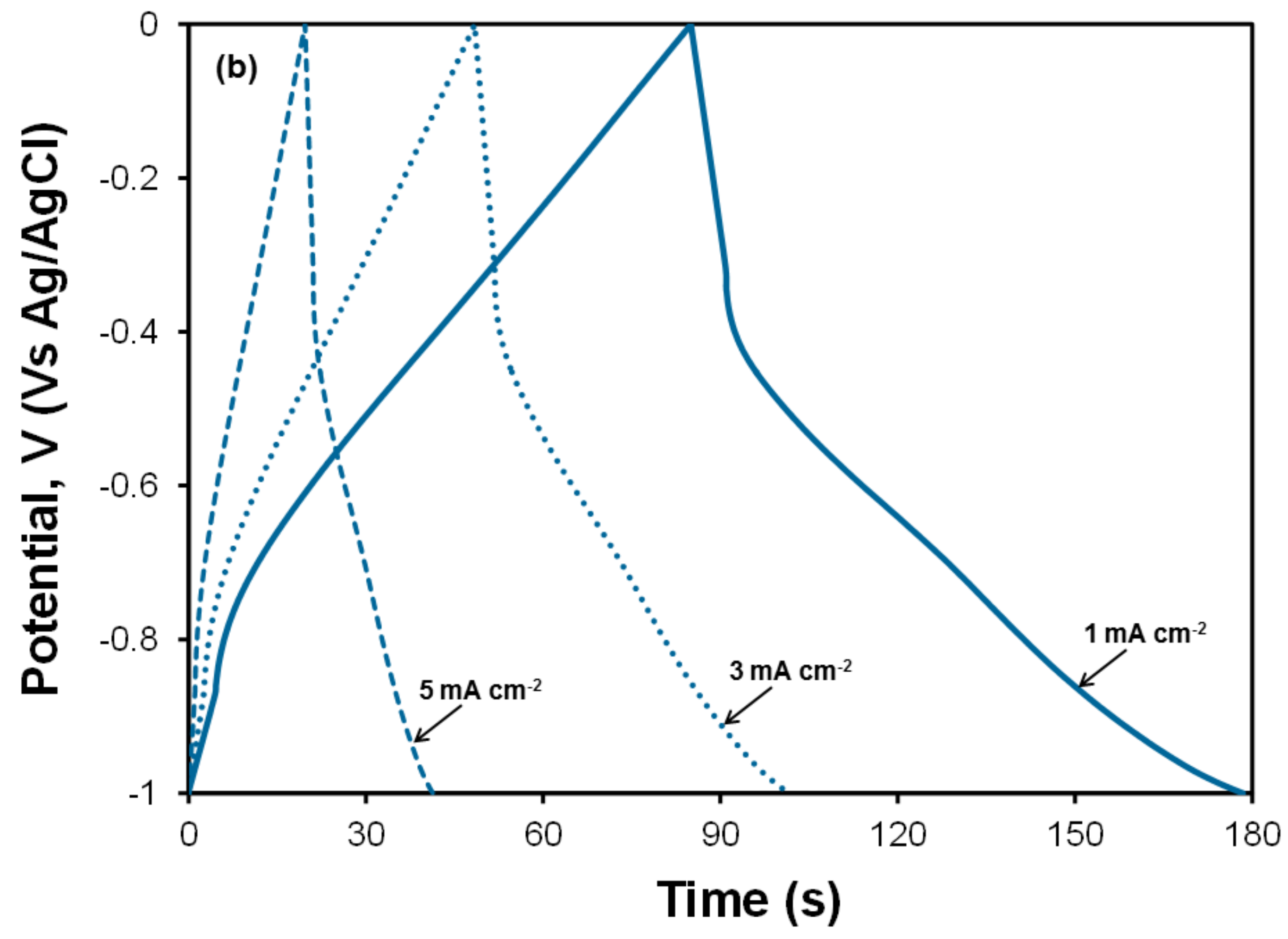


Figure 12c

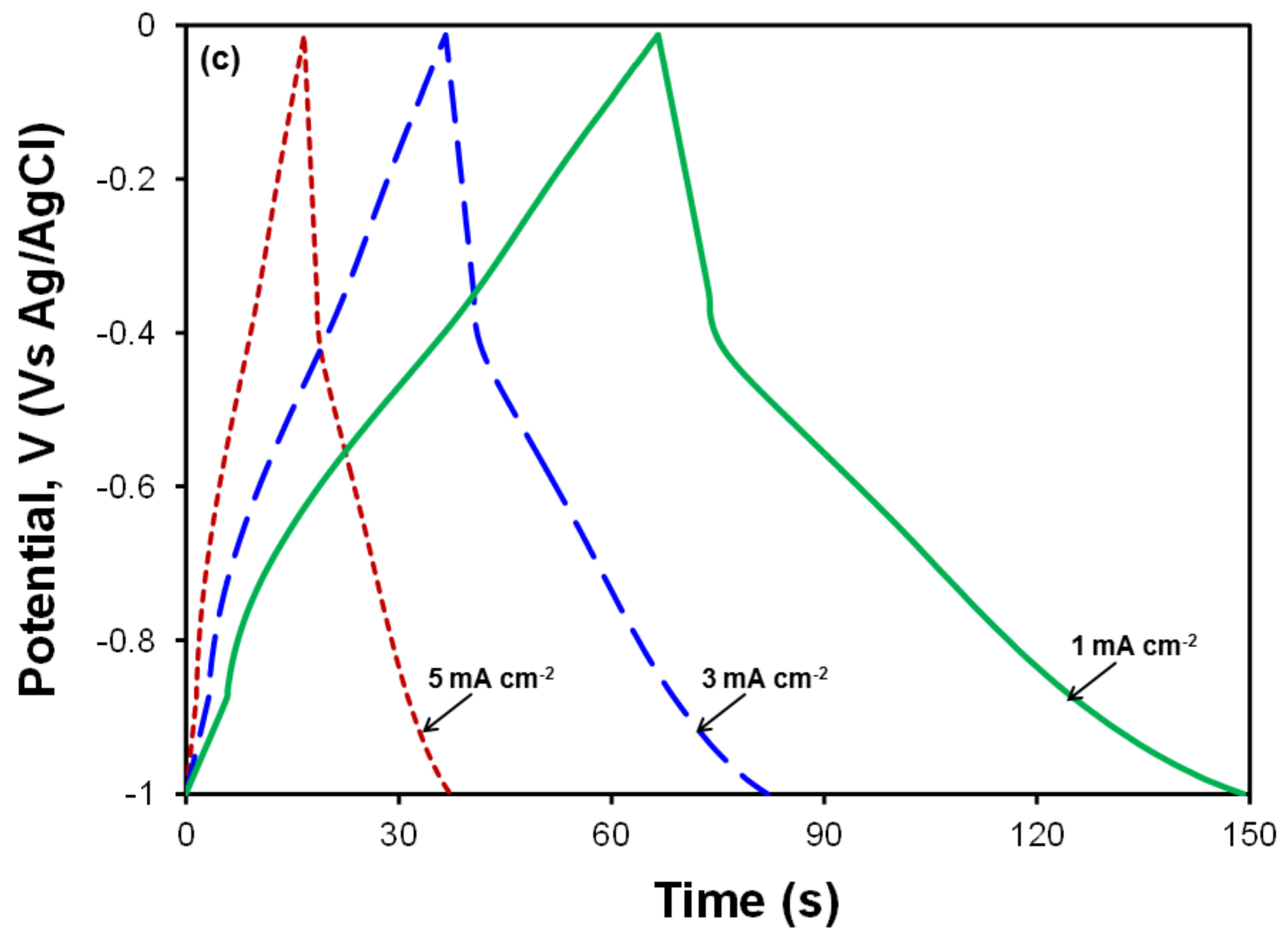




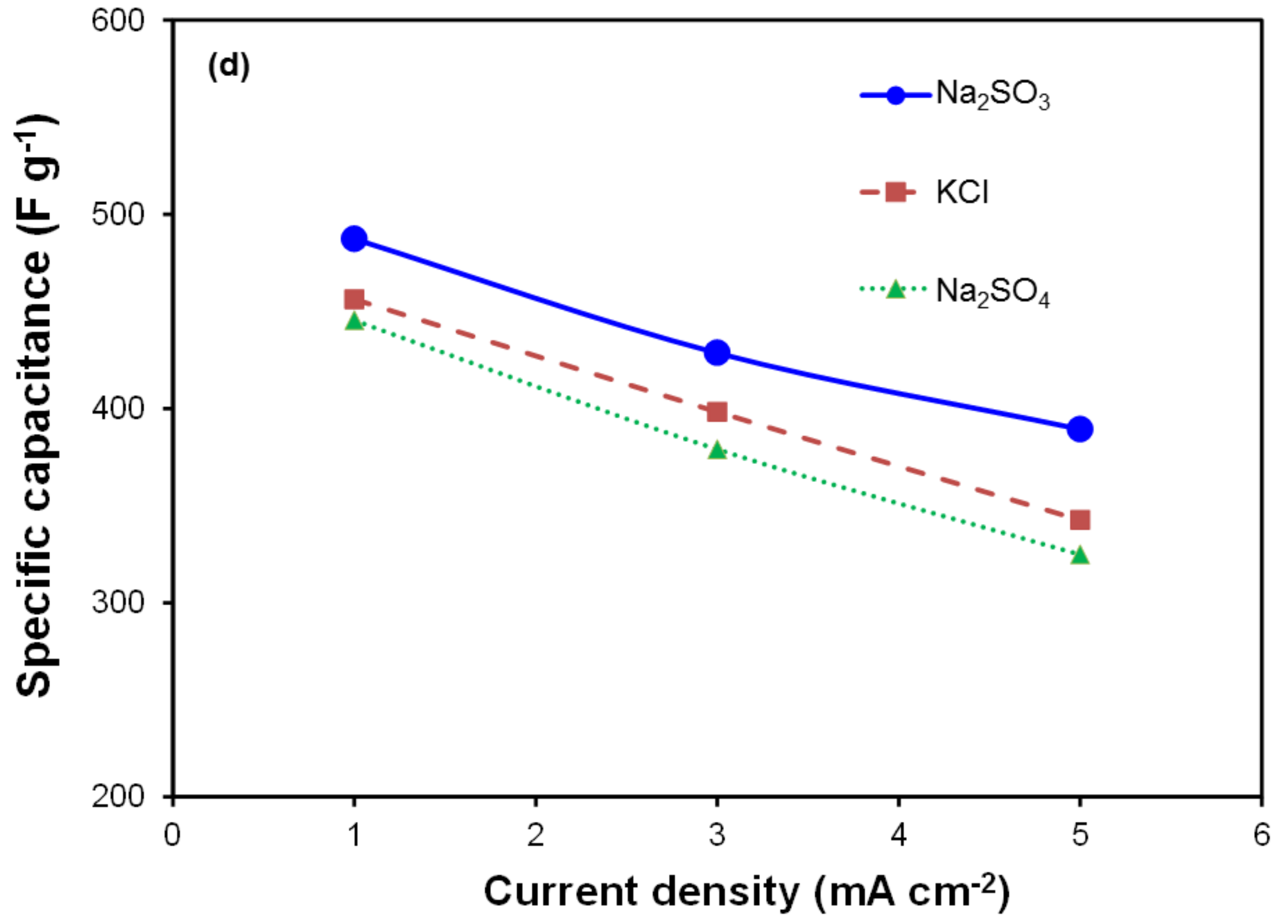


Figure 13a

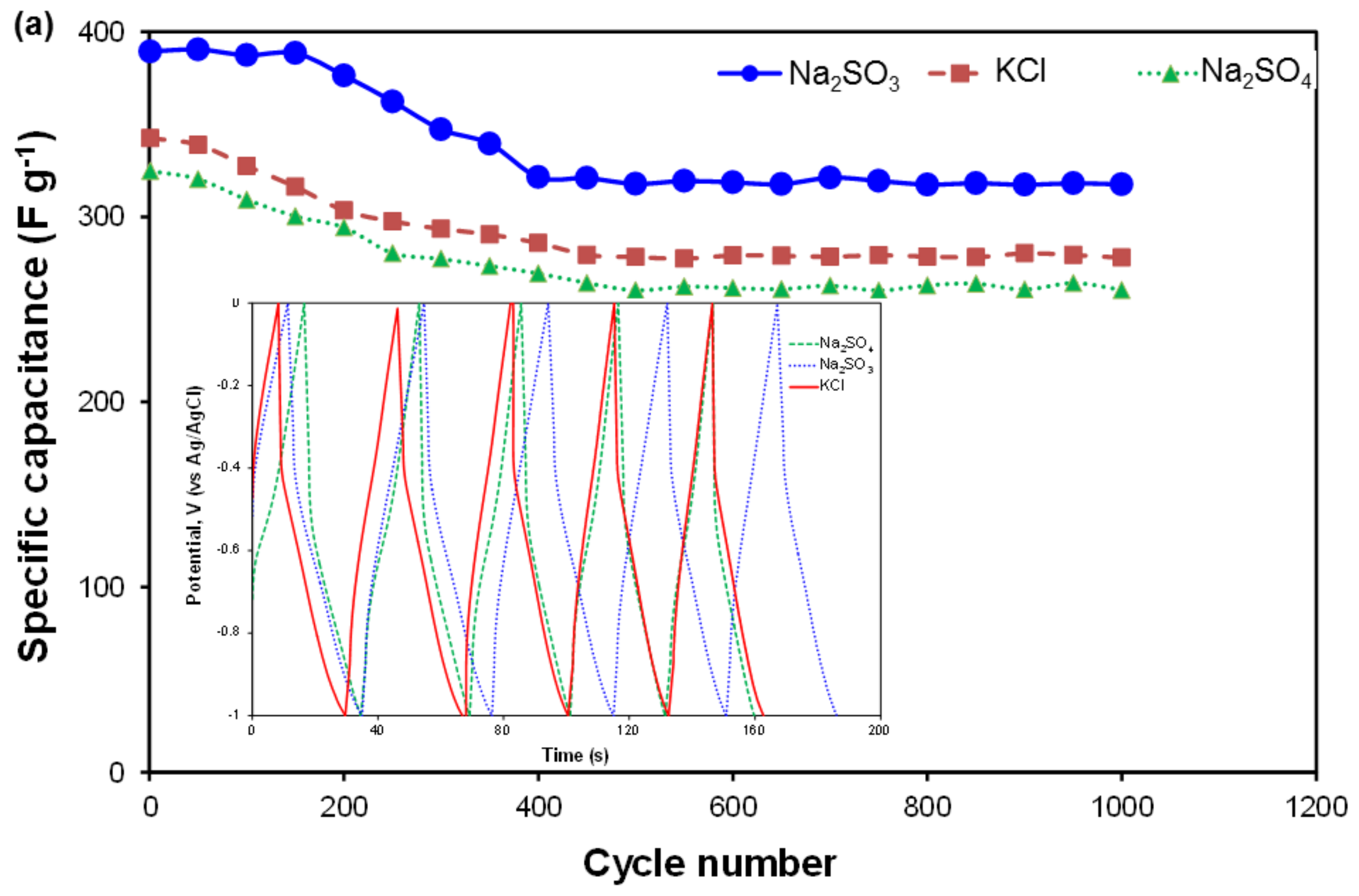




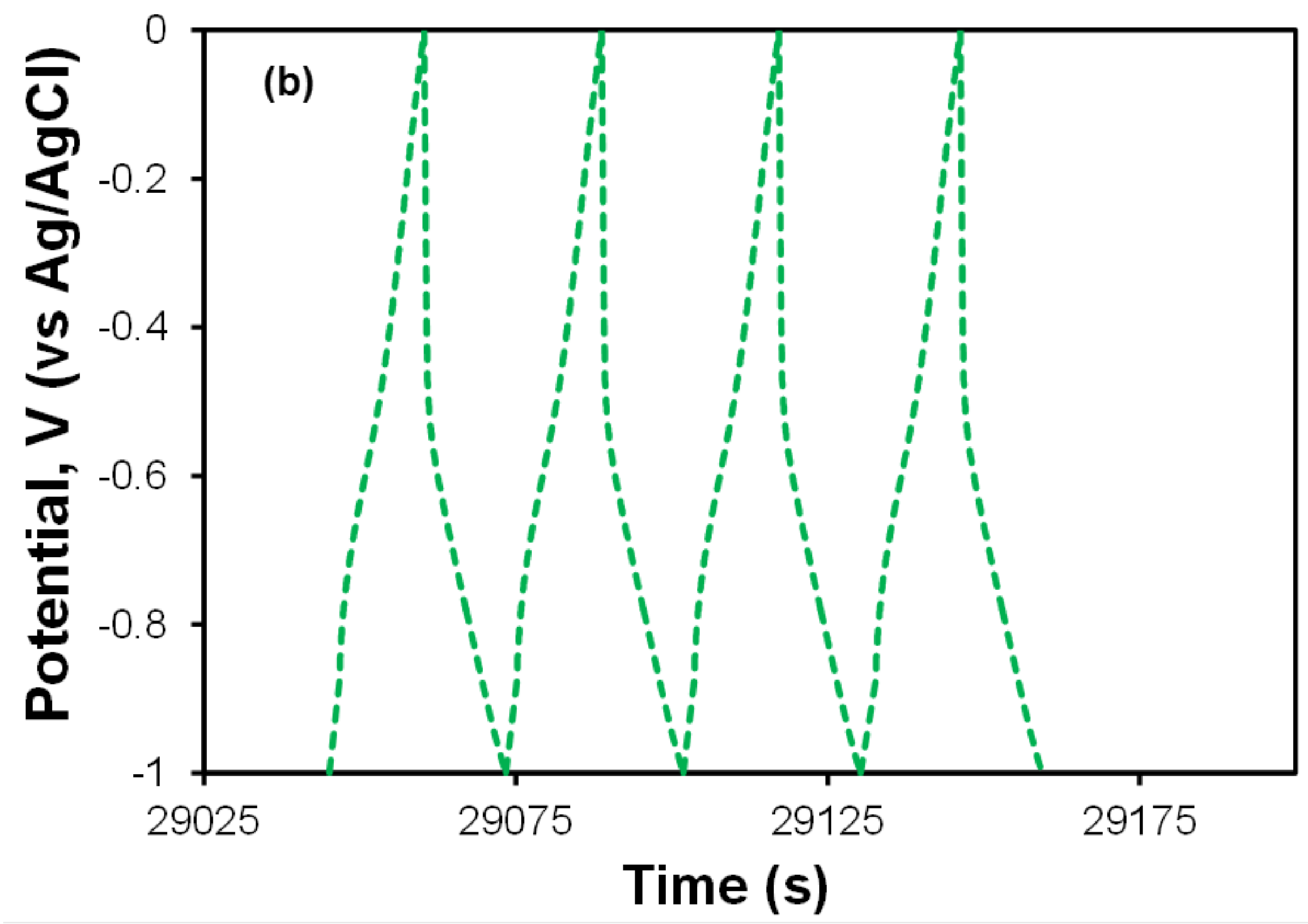




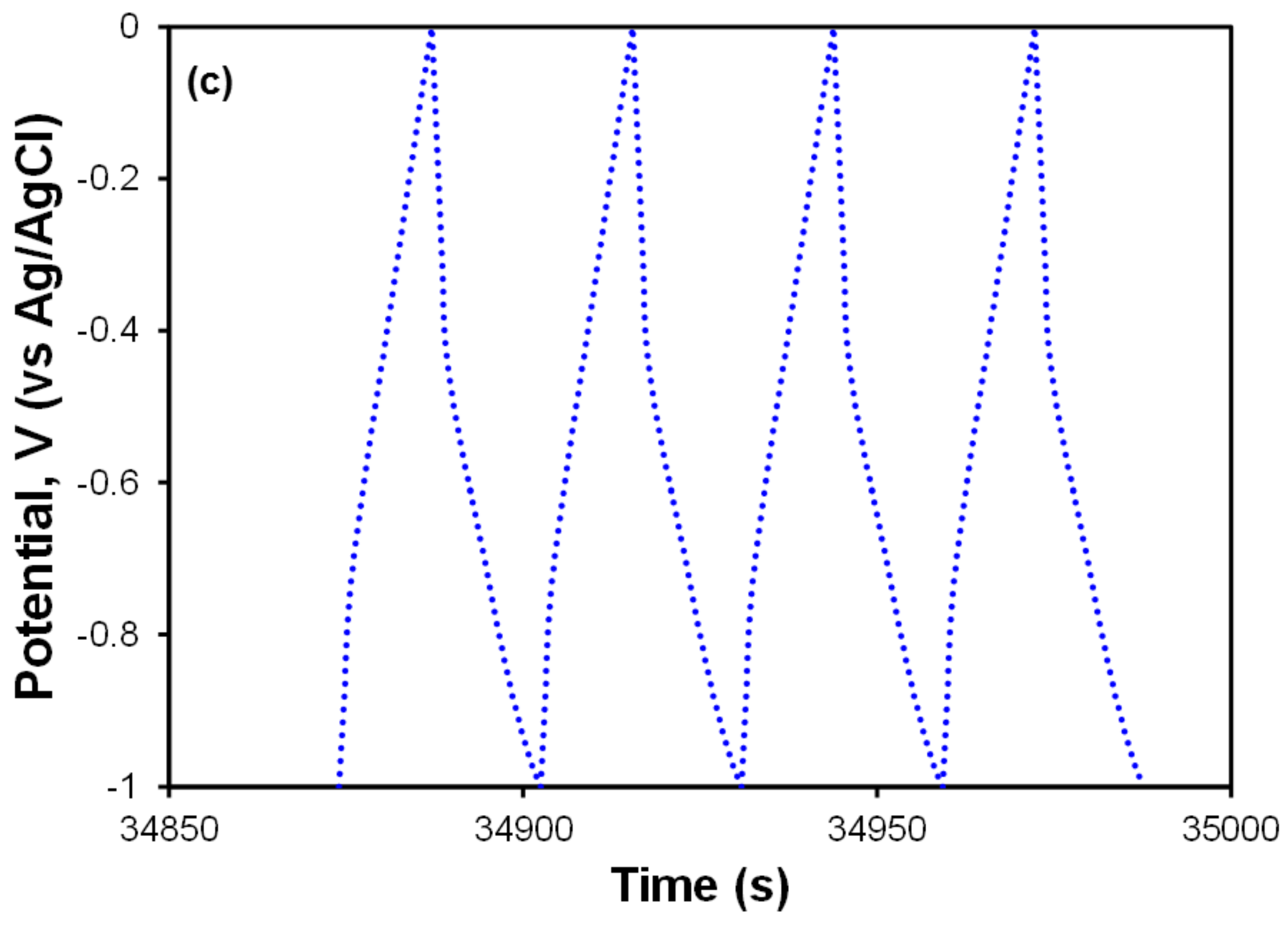


Figure 13d

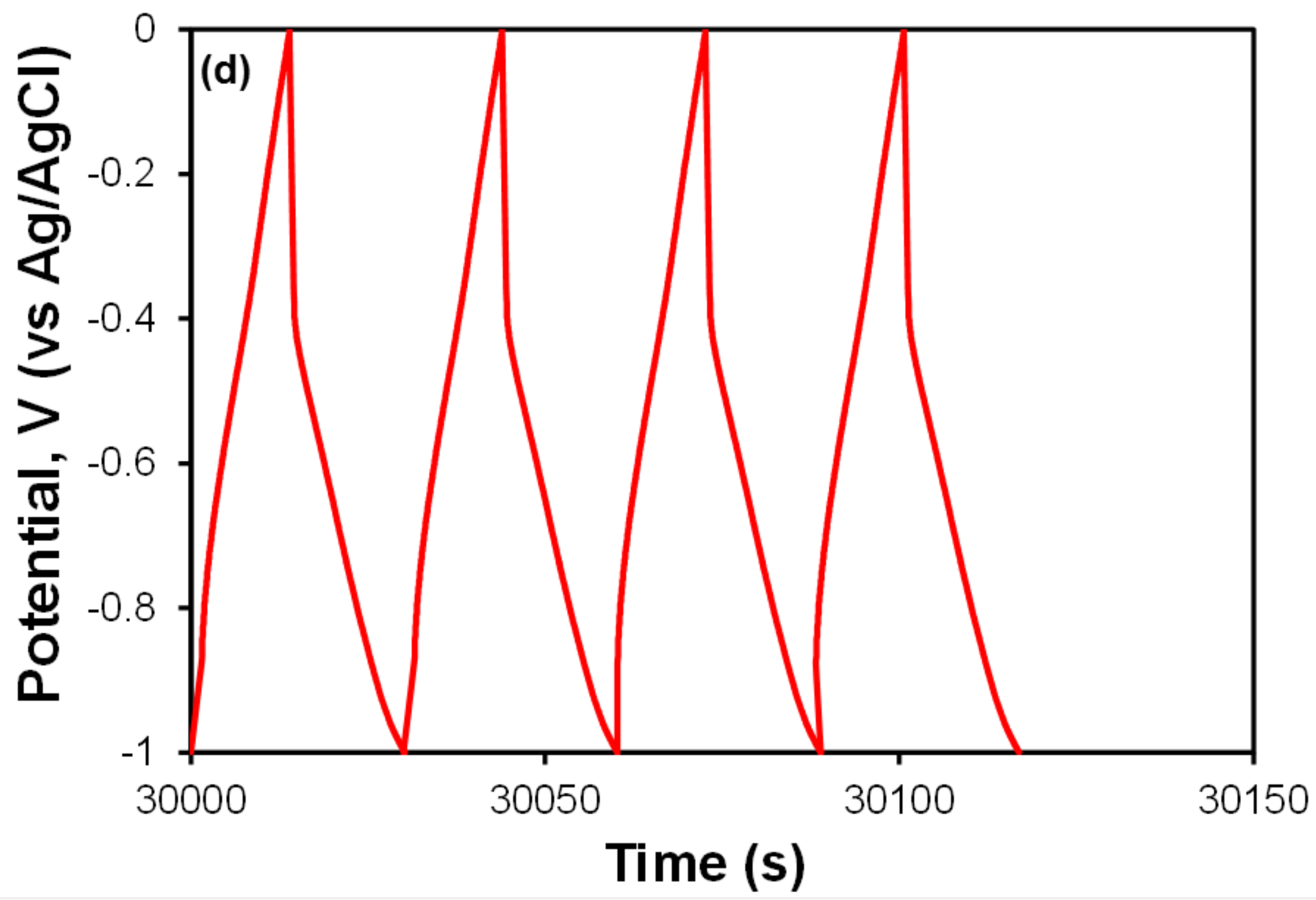


Figure 14a

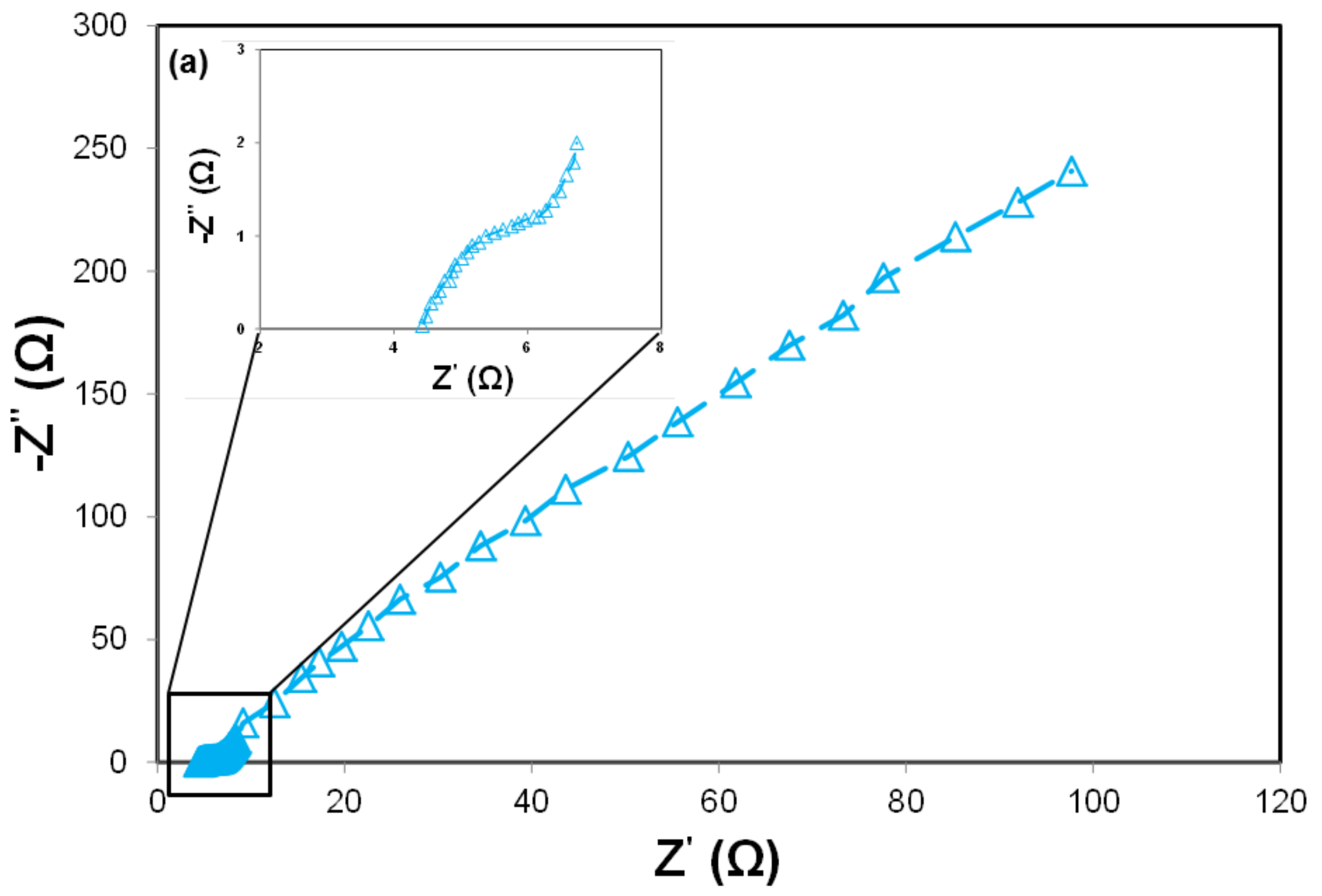


Figure 14b

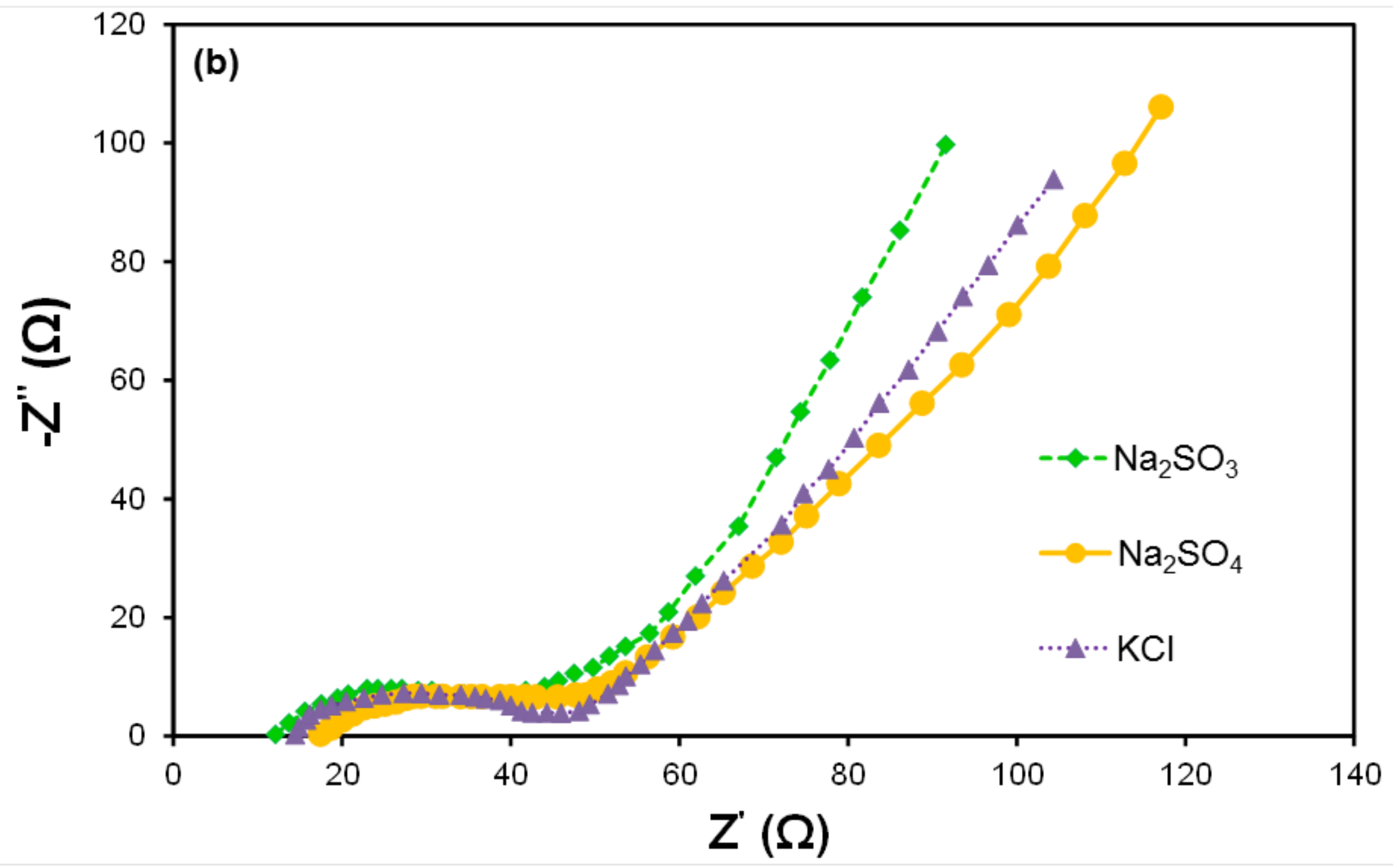

